\title{
Trends in Sustainable Synthesis of Organics by Gold Nanoparticles Embedded in Polymer Matrices
}

\author{
Antonio Buonerba ${ }^{1,2}$ (D) and Alfonso Grassi ${ }^{2, *(D)}$ \\ 1 Sanitary Environmental Engineering Division (SEED), Department of Civil Engineering, \\ University of Salerno, Via Giovanni Paolo II, 84084 Fisciano, SA, Italy; abuonerba@unisa.it \\ 2 Department of Chemistry and Biology "Adolfo Zambelli", University of Salerno, Via Giovanni Paolo II, \\ 84084 Fisciano, SA, Italy \\ * Correspondence: agrassi@unisa.it
}

Citation: Buonerba, A.; Grassi, A. Trends in Sustainable Synthesis of Organics by Gold Nanoparticles Embedded in Polymer Matrices. Catalysts 2021, 11, 714. https:// doi.org/10.3390/catal11060714

Academic Editors: Tamao Ishida and Luísa Margarida Martins

Received: 5 May 2021

Accepted: 4 June 2021

Published: 7 June 2021

Publisher's Note: MDPI stays neutra with regard to jurisdictional claims in published maps and institutional affiliations.

Copyright: (C) 2021 by the authors. Licensee MDPI, Basel, Switzerland. This article is an open access article distributed under the terms and conditions of the Creative Commons Attribution (CC BY) license (https:/ / creativecommons.org/licenses/by/ $4.0 /)$.

\begin{abstract}
Gold nanoparticles (AuNPs) have emerged in recent decades as attractive and selective catalysts for sustainable organic synthesis. Nanostructured gold is indeed environmentally friendly and benign for human health; at the same time, it is active, under different morphologies, in a large variety of oxidation and reduction reactions of interest for the chemical industry. To stabilize the AuNPs and optimize the chemical environment of the catalytic sites, a wide library of natural and synthetic polymers has been proposed. This review describes the main routes for the preparation of AuNPs supported/embedded in synthetic organic polymers and compares the performances of these catalysts with those of the most popular AuNPs supported onto inorganic materials applied in hydrogenation and oxidation reactions. Some examples of cascade coupling reactions are also discussed where the polymer-supported AuNPs allow for the attainment of remarkable activity and selectivity.
\end{abstract}

Keywords: gold nanoparticles; organic polymer support; oxidation; reduction; sustainable chemistry

\section{Introduction}

The 2030 Agenda for Sustainable Development, drawn up by United Nations (New York, NY, USA), lists the priorities for the achievement of a sustainable development in its three dimensions - economic, social, and environmental. With regard to the latter, scientists aim to design a world in which consumption and production patterns are sustainable, which means the reagents and final products must be consumed in a chemical process at a rate comparable to their regeneration without compromising human health and the environment. Moreover, the natural resources have to be wisely addressed to the production of energy, chemicals, and materials; when possible, renewable feedstocks must be preferred to the fossil-based analogues.

Sustainable catalysis plays a crucial role in the design of green chemistry; it actually allows one to improve reactants conversion and product selectivity, to reduce the amount of energy and solvents consumed during the process, to avoid purification steps, and for the protection/deprotection of functional groups; cascade reactions or multifunctional catalysis are the best option if possible [1-4].

In the last two centuries, noble metals catalysts have been extensively applied in a wide range of chemical reactions of interest for a sustainable growth: they are essential for the reduction of air and water pollution and contribute thereby to reducing the emission of products harmful to human health and the environment [5].

The majority of the industrial catalysts are heterogeneous in nature and display highsurface-area support where the active component consists of very small metal particles of dimensions of 1-20 nm often referred to as metal nanoparticles (MNPs) [6]. The Sabatier reaction for the catalytic reforming of gasoline is one the first pioneering examples of large-scale industrial applications of heterogeneous catalysis based on noble metals [7]. 
Nanometric sized Pt-particles supported onto chlorinated alumina were introduced in 1960s in petroleum refining, enabling the octane rating of naphtha to be greatly increased [8]. MNPs of noble metals (e.g., $\mathrm{Pd}, \mathrm{Pt}, \mathrm{Au}, \mathrm{Ag}$, and $\mathrm{Ru}$ ) have been applied in catalytic hydrogenation for the remediation of contaminated water/soil, e.g., nitroaromatics reduction, hydrodehalogenation of polychlorinated biphenyls (PCBs) and perfluorochemicals, and detoxicity of heavy metals [5].

In the last decades of the nineteenth century, gold unexpectedly appeared as an attractive and promising metal catalyst. The pioneering studies by Haruta et al., showed how the "yellow metal" is very efficient, at the nanometric scale, in aerobic oxidation of CO to $\mathrm{CO}_{2}$ under very mild conditions and sub-ambient reaction temperature [9]. Since then, gold nanoparticles (AuNPs) have been successfully applied in a wide array of chemical reactions where the catalytic activity is generally lower than other noble metals but gold reviles for higher selectivity; examples include the reduction of carbon-carbon triple bond or of nitroarenes, aerobic oxidation of alcohols, and carbon-carbon bond formation [6]. For large-scale application, the price of gold is a critical feature; however, it is comparable to that of palladium and platinum, and significantly lower than rhodium. The annual bulk production of gold is of 3700 metric tons per year vs. about 230 for Pt and 290 tons for palladium, or 30 tons for ruthenium and rhodium.

The size and shape of the AuNPs strongly influence the chemisorption of substrates, intermediates, and products, thus affecting the final catalytic performances [10]; typically, nanoparticles of $1 \mathrm{~nm}$ or lower and/or multidefective AuNPs led to the best activity values. The investigation of the surface morphology also allowed one to assess how distinct arrangements of the metal atoms located on different crystalline planes affect chemisorption and reactivity [11]. The composition and morphology of bimetallic nanoparticles of gold with other noble metals, as e.g., palladium or platinum, were also designed to improve catalytic activity and selectivity [12].

The AuNPs are typically deposited/embedded onto a solid support to favor catalyst recovery and recycling, and hamper sintering or leaching of the metal during reactions carried out under harsh reaction conditions. Porous supports have been also proposed for the design of multifunctional catalysts to increase the selectivity of the reaction by controlling, e.g., the accessibility of the reactants to the catalytic sites $[13,14]$.

Heterogeneous catalysis by AuNPs has been extensively reported in recent excellent review articles covering the synthesis of mono metallic and bimetallic AuNPs, their morphological control, and their catalytic applications [6,15-17]. In this review, we aim to describe the synthesis and catalytic properties of AuNPs supported/stabilized by polymers of organic monomers. This class of supports received less attention in the literature because of its poor thermal stability at temperature higher than, e.g., $200^{\circ} \mathrm{C}$, and its reduced efficiency in stabilizing the MNPs under these conditions. However, polymer matrices offer a number of real advantages: (i) the hydrophilic and hydrophobic properties of the support can be tuned by appropriate functionalization of the surface, making the catalyst impregnable in solvents or organic reagents with different polarity; (ii) functional groups containing donor atoms can be introduced via routine organic reactions to stabilize the MNPs; (iii) covalent functionalization of the support with Brønsted acid and base functionalities allows for the modulation of the $\mathrm{pH}$ of the reaction medium, making unnecessary the further addition of acids or bases often required for the catalytic performances; (iv) polymer morphology can control the accessibility of the organic reactants to the catalytic sites embedded in the polymer matrix leading to multifunctional catalysts; (v) processing of the polymer matrix via conventional procedures allows for the production of the catalysts under the form of films, beads, and foams properly addressed to the reactor design.

\section{Synthesis and Properties of AuNPs Embedded in Polymer Matrices}

Most the procedures for the synthesis of supported AuNPs for catalytic applications can be subdivided into four main categories, namely: impregnation, depositionprecipitation, co-precipitation, and colloid deposition [18-20]. Impregnation is one of the 
simplest methods for preparation of gold catalysts. The powder support is treated with a solution of the gold precursor, dried, and thermal-treated for the reductive decomposition the precursor to metallic nanoparticles. In the deposition-precipitation method, a solution of a gold(III) compound, generally $\mathrm{HAuCl}_{4}$, is compounded with a suspension of the support particles, and the precipitation of the gold precursor in the form of hydroxide onto the surface of the support is afforded by a gradual rising of the $\mathrm{pH}$. The final catalytic system is obtained by filtration, washing, drying, and a thermal treatment, also in this case, applied for the reduction of the gold precursor. Deposition-precipitation was one of the earliest strategies for preparation of supported AuNPs. Haruta and co-workers applied this synthetic route for the preparation of AuNPs supported on titanium dioxide for catalytic oxidation of carbon monoxide [21,22]. Co-precipitation consists in the simultaneous precipitation of gold and support precursors by increasing the $\mathrm{pH}$. Gold particles supported on oxides such as $\mathrm{Fe}_{2} \mathrm{O}_{3}, \mathrm{NiO}$, and $\mathrm{Co}_{3} \mathrm{O}_{4}$ can be obtained with this method. Gold precursor, typically $\mathrm{HAuCl}_{4}$, and support precursor, often in the form of nitrate salt, are combined in solution and the $\mathrm{pH}$ adjusted by addition of sodium carbonate. In this way, gold precipitates in the form of hydroxide and the metal precursor of the support precipitates in the form of carbonate. The precipitate, similarly to the previous procedures, is than filtered, dried, and thermal-treated for the reduction of the gold and the calcination of the carbonate to the corresponding oxide as a support for the AuNPs. Several modifications and implementations have been applied, e.g., photochemical, sonochemical, or spay depositions [18]. The use of halogen-free gold and support precursors results in catalytic systems with smaller AuNPs and improved size distribution and particle dispersion. Using this method, during the thermal treatment for the reduction of the gold III or I precursors, the formation of polymeric $\mathrm{Au}(\mathrm{I})$-halogen that leads to sintering of the nanoparticle in formation is avoided [18]. Finally, colloid deposition is a synthetic technique where gold colloids are formed before being immobilized on the support. Several chemical reducing agents can be used such as hydrogen, carbon monoxide, hydrazine, hydrides, such as sodium borohydride, or salts (i.e., sodium citrate), as well as alcohols, and reducing agents derived from natural sources. The strength of the reducing agent affects size and size distribution and dispersion in polymer matrix: strong reducing agents afford smaller and well-dispersed particles.

The above-described techniques were initially developed for the synthesis of AuNPs supported by inorganic compounds and cannot be applied directly, without appropriate modifications, for the synthesis of polymer supported AuNPs. Procedures requiring high temperature treatments for gold precursor decomposition to metallic gold, such as deposition-precipitation and co-precipitation, cannot be used in presence of organic polymer matrices, due to the side-decomposition of the support. Nevertheless, thermal treatments at moderate temperature $\left(<200{ }^{\circ} \mathrm{C}\right)$ can be applied in presence of polymer matrices that accomplish both the functions of reducing agent and stabilizer.

Impregnation and colloid deposition are the principal routes for production of polymer supported AuNPs for catalytic applications. The synthetic procedures for synthesis and characterization of AuNPs supported by inorganic and polymer matrices were recently reviewed, respectively, by Prati et al. [19] and Dzhardimalieva et al. [23,24]. The controlled synthesis of gold colloids in the presence of polymers has been additionally exploited for the deposition of AuNPs onto inorganic supports. This strategy consists of the transfer of AuNPs stabilized by polymer wrapping to an inorganic solid support. The colloidal suspension is thus compounded with the support and the removal of the solvent that affords the deposition of the AuNPs-polymer composite onto the surface of the inorganic support, which is then heated for the decomposition of the polymer matrix to produce naked AuNPs finely deposited onto the inorganic support. This methodology allows for improved control of the size and morphology of the nanoparticles; the direct synthesis in the absence of the polymer stabilizer, via, e.g., fast reduction of the metal precursor in presence of the inorganic support, results in a poor control of the nanoparticle size and morphology, and of the metal loading in the catalyst. 
The synthesis of AuNPs in presence of natural and synthetic polymer stabilizers allows for the efficient control of the particles' size, size distribution, and dispersion. The nucleation and growth of gold colloids, as initially proposed by LaMer (see Figure 1), is comprised of three stages: (i) reduction of the gold precursor, from +1 or +3 oxidation state to the metallic state; (ii) formation of colloids via nucleation of the monomers; and (iii) growth of the colloids via Ostwald ripening $[25,26]$. Colloids are particles unaffected by gravity, but they can experience the Brownian motions; their growth occurs by aggregation of nuclei or coalescence of the small particles driven by Brownian forces. The presence of polymer chains under gel-like conditions allows for the nucleation stage and slows down the growth of the particles or their coalescence.

c)

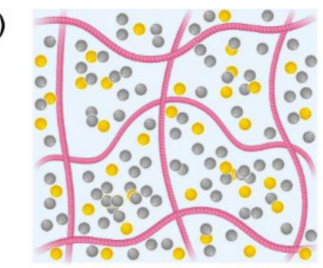

b)

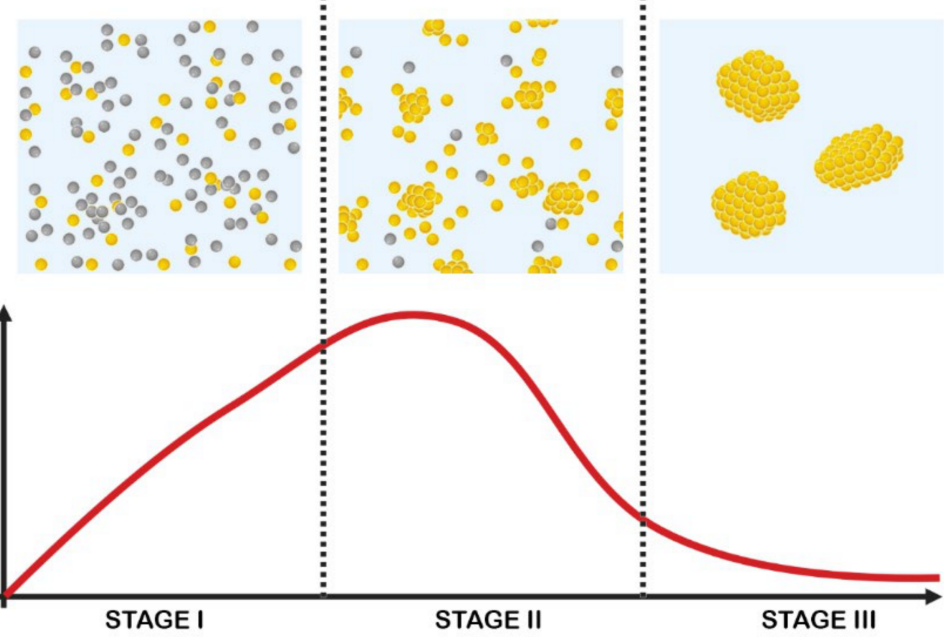

Figure 1. Gold nanoparticle growth according to LaMer's mechanism (a), in absence (b) and in presence of polymer chains (c).

Synthetic and natural polymers have been extensively used as stabilizer of AuNPs: poly( $N$-vinyl-2-pyrrolidone) [27], polyacrylates [28,29], poly(ethylene glycol), alginate [30,31], polysaccharides [32], chitosan [33,34], polystyrenes [35,36], polystyrene-polybutadiene block copolymers [37], poloxamers block copolymers [38-40], poly( $\varepsilon$-caprolactone)-poly(Nvinyl-2-pyrrolidone) block copolymers [41], poly(ethylene glycol)-polyethylenimine-poly( $\varepsilon$ caprolactone) [42], poly(ethylene glycol)-poly(vinyl alcohol) block copolymers [43], redoxactive polymers [44], negatively charged polyelectrolytes such copolymers of 4-styrenesulfonate and maleic acid (P(SS-co-MA) [45], and biomacromolecules such as bovine serum albumin [46] or enzymes [47].

The pioneering synthesis of polymer-stabilized AuNPs can be attributed to Faraday, who first used gelatin as both protective and reducing agent of the gold precursors [48]; this synthetic method has been almost completely abandoned after Turkevich [49] and Frens [50] described the synthesis of narrowly size dispersed AuNPs using citrate as reductant and alkylthiols as stabilizing agent in monophasic or biphasic solvents. The synthesis of polymer-supported AuNPs can be further classified in physical-chemical methods [24,51] and chemical wet methods [20,52-54]. Physical-chemical methods comprise ex-situ synthesis where the metal particles are generated externally to the polymer and then mixed together [55] and in situ synthesis of AuNPs-polymer composites obtained via reduction of a gold precursor in the presence of the polymer. The latter approach is simple, rapid, 
cost-effective, does not require sophisticated equipment, and leads to the synthesis of well-controlled sizes and shapes of AuNPs to be applied in catalysis [17,20,24,53,56-61].

Four main categories of polymer supported/stabilized AuNPs have been developed (Figure 2) [17]. Deng et al., impregnated a cationic exchange resin with $\mathrm{HAuCl}_{4}$ and heated the mixture at $333 \mathrm{~K}$; the polymer acts as reducing agent of the gold precursor and as support of the AuNPs (Figure 2d) [62]. A similar approach was later applied by Haruta et al., using an anion exchange resin (Figure 2d) [17]. Corain et al., impregnated a polyacrylic resin, bearing thioether functionalities, with $\mathrm{AuCl}_{3}$ and carried out the reduction with $\mathrm{NaBH}_{4}$ to obtain the template synthesis of AuNPs into the resin cavities (Figure 2b) [63]. Tsukuda et al., used the water-soluble polymer poly( $N$-vinylpyrrolidone) (PVP) as stabilizer of AuNPs resulting from aqueous solutions of $\mathrm{HAuCl}_{4}$ and $\mathrm{NaBH}_{4}$ (Figure 2a) [64]. PVP acts as an agent for the (pre)reduction of the gold precursor from $\mathrm{Au}^{3+}$ to $\mathrm{Au}^{+}$and as capping agent for the NPs in place of a solid support [65]. Kobayashi et al., (Figure 2c) used a thermally-curable polystyrene, bearing epoxy and hydroxyl pendant functionalities [36]. $\left(\mathrm{Ph}_{3} \mathrm{P}\right) \mathrm{AuCl}$ and $\mathrm{NaBH}_{4}$ were sequentially added to a THF solution of the polymer and coacervation of the polymer-AuNPs composite was thus obtained in hexane. The polymer mixture was isolated by filtration, dried, and finally heated at $150{ }^{\circ} \mathrm{C}$ to yield crosslinking of the support and produce the polymer incarcerated AuNPs (AuNPsclPS). Grassi et al., simplified this approach, synthesizing AuNPs supported in a stereo- and regio-regular polymer matrix consisting of syndiotactic polystyrene-cis1,4-poly(butadiene) multiblock copolymer (sPSB) (Figure 3) $[37,66] . \mathrm{HAuCl}_{4}$ and $\mathrm{NaHB}(\mathrm{Et})_{3}$ were sequentially compounded in the THF solution of the polymer support, and the composite (AuNPs-sPSB) was recovered by precipitation in methanol, filtration, and drying. The synthetic procedure affords the quantitative incorporation of the AuNPs, allowing for easy control of the gold loading (Figure 3). The sPSB polymeric support is nanoporous, semicrystalline, and polymorphic, conferring peculiar properties to the catalytic system (vide infra) [37,67-69].

a) Tsukuda

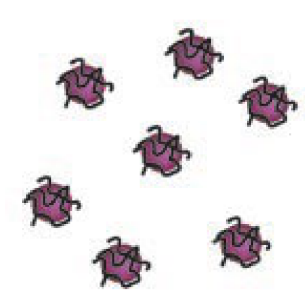

c) Kobayashi

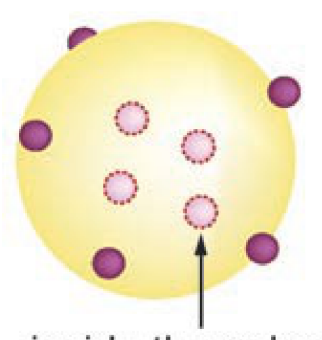

inside the polymer particle b) Corain

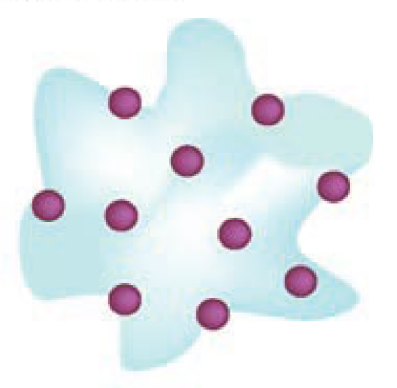

d) Deng and Haruta

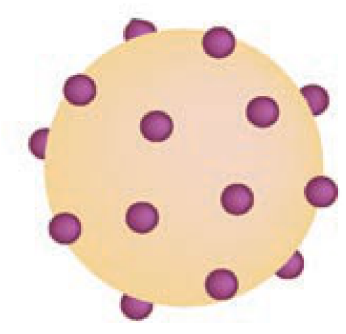

Figure 2. Examples of polymer supported AuNPs for application in catalysis. AuNPs stabilized by water-soluble polymers (a), embedded in pores of functionalized resins (b), incarcerated in cross-linked polymer (c), and supported on polymer surface (d). Reproduced with permission from reference [17]. 


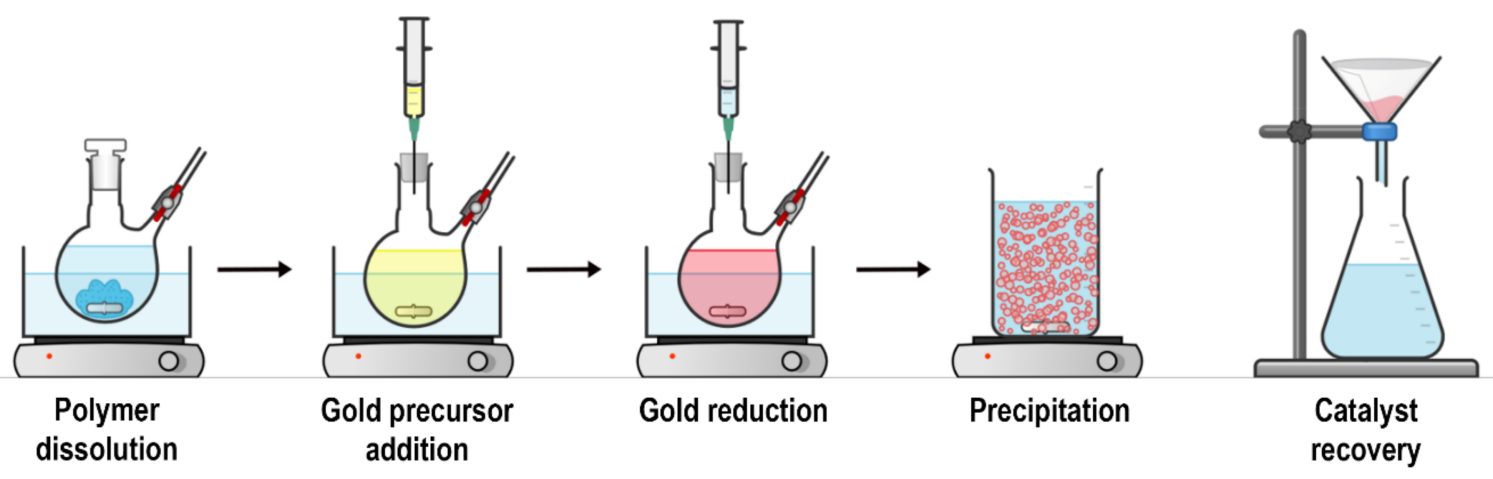

Figure 3. Synthesis of AuNPs supported by sPSB. Adapted with permission from reference [37].

\section{Catalytic Properties}

\subsection{Selective Hydrogenation Reactions}

Catalytic hydrogenation is one of the most important reactions extensively carried out in both industry and organic synthesis laboratories. If more than one functional group is in the substrate, the main challenge is to address the reaction toward the target molecule with high chemoselectivity. Group 8-10 metals such as $\mathrm{Ni}, \mathrm{Pd}, \mathrm{Ru}$, and $\mathrm{Pt}$ are the metals of choice in this reaction because of their high activity. In comparison, $\mathrm{Au}$ is less attractive because of the sluggish dihydrogen activation that typically requires harsher reaction conditions, but Au excels in chemoselective reduction of unsaturated functional groups under sustainable conditions [70]. AuNPs supported onto inorganic metal oxides have been successfully applied in, e.g., selective hydrogenation of 1,3-butadiene to 1-butene ( $\mathrm{Au}-\mathrm{SiO}_{2}[71] ; \mathrm{Au}-\mathrm{Al}_{2} \mathrm{O}_{3}$ [72]; $\left.\mathrm{Au}-\mathrm{ZrO}_{2}[73,74]\right)$ and reduction of $\alpha, \beta$-unsaturated aldehyde to the corresponding allyl alcohols.

\subsubsection{Hydrogenation of Unsaturated Carbon-Carbon Bonds}

Semihydrogenation of alkynes and chemoselective hydrogenation of diolefins are among the most challenging reactions in sustainable catalysis (Table 1). AuNPs and bimetallic (Pd\&Au)NPs embedded in polystyrene-block-poly-4-vinylpyridine (PS- $b$-P4VP) of different molecular weights $\left(M_{\mathrm{W}}=149,000 \mathrm{~g} / \mathrm{mol} ; M_{\mathrm{w}}=22,500 \mathrm{~g} / \mathrm{mol}\right)((\mathrm{Au} \& P d) N P s-$ (PS-b-P4VP)) [75] were synthesized by reduction of the metal precursors $\left(\mathrm{HAuCl}_{4} ; \mathrm{PdCl}_{2}\right)$ with a variety of reductants such as $\mathrm{N}_{2} \mathrm{H}_{4}, \mathrm{C}_{6} \mathrm{H}_{5} \mathrm{NHNH}_{2}, \mathrm{NaBH}_{4}, \mathrm{Et}_{3} \mathrm{SiH}$, and $\mathrm{LiB}\left(\mathrm{C}_{2} \mathrm{H}_{5}\right)_{3} \mathrm{H}$ to yield big, strongly segregated micelles with a hydrodynamic radius of $77 \mathrm{~nm}$ and $32 \mathrm{~nm}$. The AuNPs-(PS- $b$-P4VP)] and (Pd\&Au)NPs-(PS- $b$-P4VP)] catalysts were tested in the reduction of cyclohexene, 1,3-cyclooctadiene, and 1,3-cyclohexadiene using dihydrogen as reductant under mild conditions $\left(30^{\circ} \mathrm{C} ; \mathrm{P}_{\mathrm{H} 2}=1.1 \mathrm{~atm}\right)$. The bimetallic (Pd\&Au)NPs catalysts, with a Pd-shell and Au-core morphology, exhibited performances higher than PdNPs, independently of their composition ( $\mathrm{Au} / \mathrm{Pd}$ molar ratio of $1 / 5,1 / 4,1 / 3)$; noteworthily, the monometallic AuNPs are inactive under the same conditions.

Table 1. Hydrogenation of C-C unsaturated bond catalyzed by AuNPs and dihydrogen.

\begin{tabular}{|c|c|c|c|c|c|}
\hline Catalyst & Substrate & $\begin{array}{c}\text { Conv. } \\
(\%)\end{array}$ & Main Product & $\begin{array}{c}\text { Select. } \\
(\%)\end{array}$ & Reference \\
\hline $\begin{array}{c}\text { (Au\&Pd)NPs-(PS- } \\
\text { b-P4VP) } \\
(\text { Au:Pd = 1:4) }\end{array}$ & cyclohexene & 65.7 & cyclohexane & $>99$ & $\begin{array}{l}\text { (Seregina et al., } \\
\text { 1997) [75] }\end{array}$ \\
\hline $\begin{array}{c}\text { (Au\&Pd)NPs-(PS- } \\
\left.b \text {-P4VP\& } \mathrm{Al}_{2} \mathrm{O}_{3}\right) \\
(\mathrm{Au}: \mathrm{Pd}=1: 5)\end{array}$ & cyclohexene & 72.5 & cyclohexane & $>99$ & $\begin{array}{c}\text { (Seregina et al., } \\
\text { 1997) [75] }\end{array}$ \\
\hline
\end{tabular}


Table 1. Cont.

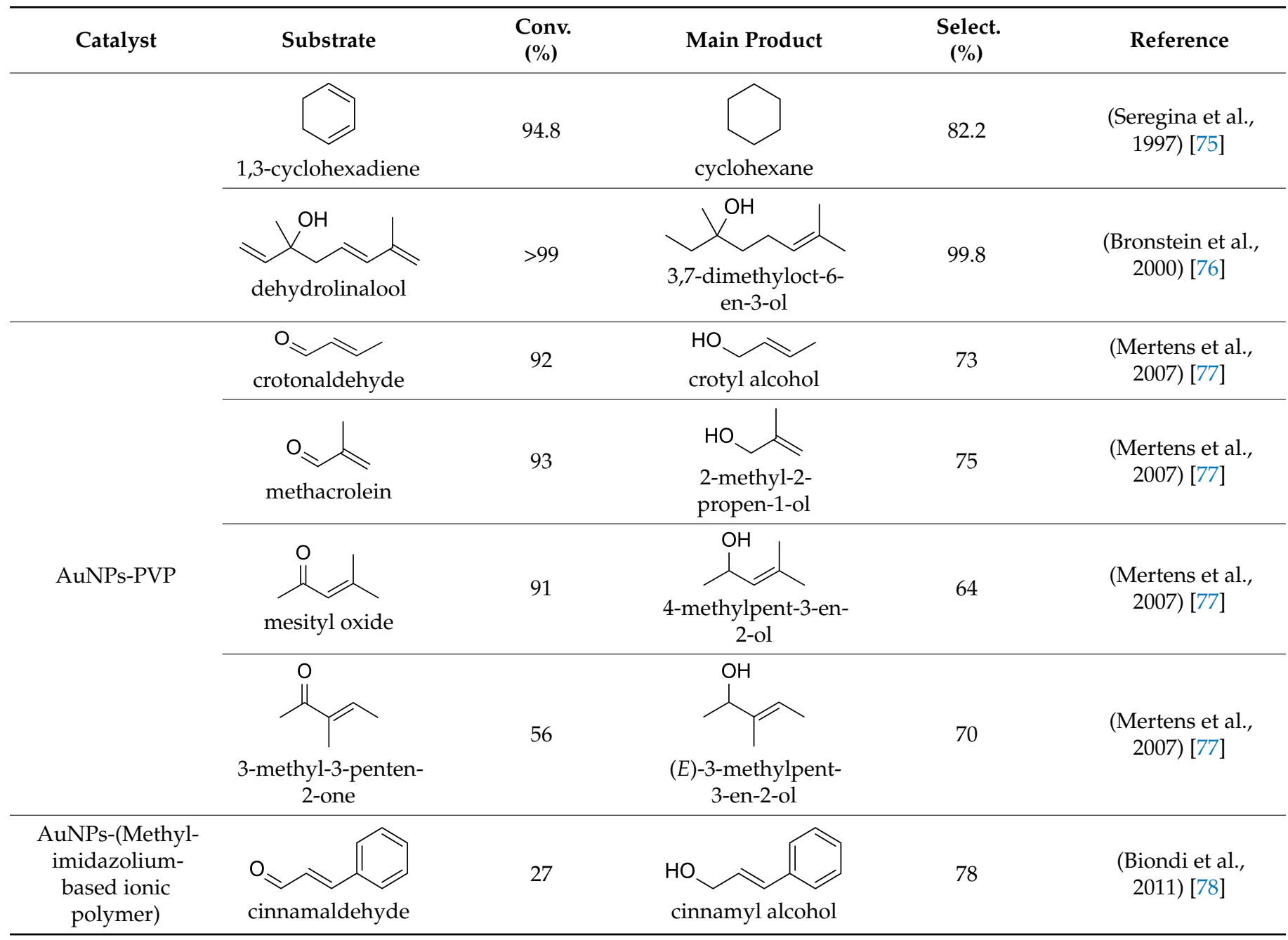

The deposition of the (Au\&Pd)-(PS- $b$-P4VP) micelles onto $\mathrm{Al}_{2} \mathrm{O}_{3}$ support gave thermally more stable and recyclable catalyst with no loss of activity and selectivity after six catalytic runs. Cyclohexadiene was reduced to cyclohexene with a rate comparable to that of the commercial PdNPs-C but with higher selectivity ( $82 \%$ vs. $55 \%)$. The (Au\&Pd)NPs(PS-b-P4VP) catalyst was also investigated in dehydrolinalool hydrogenation [76]. High selectivity was achieved (99.8\%) at 100\% conversion of the substrate; also in this case, the activity of the bimetallic catalyst is higher than monometallic PdNPs. FTIR spectra of CO adsorbed onto the (Au\&Pd)NPs surface showed only one band attributed to the terminal coordination of the probe molecule to Pd atoms on the nanoparticle surface. These findings were interpreted by the authors assuming the existence of only one type of Pd active center where a competitive coordination of both the substrate and hydrogen occurs. Kinetic study along with computational kinetic models allowed for the describing of hydrogenation mechanism. The Pd shell is poor in electron density because of the Au core, and the positively charged Pd surface binds pyridine units of P4VP more strongly, providing a denser packing of the modifying ligands that yields a more uniform particle surface with only one kind of active center.

\subsubsection{Hydrogenation of $\alpha-\beta$-Unsaturated Carbonyl Compounds}

The chemoselective hydrogenation of $\alpha, \beta$-unsaturated aldehydes and ketones is in the focus of research interest since allyl alcohols are valuable intermediates in the production of various fine chemical, pharmaceutical, and cosmetic compounds [79]. Pd and $\mathrm{Pt}$ nanocatalysts generally are very active in hydrogenation of unsaturated carbon- 
carbon bonds, and this reaction is kinetically and thermodynamically favored compared to hydrogenation of the carbonyl functionalities. Although less active, gold showed remarkable chemoselectivity in the reduction of acrolein, crotonaldehyde, cinnamaldehyde, mesityl oxide, and citral to the corresponding allyl alcohols. Preliminary results showed that AuNPs supported on inorganic oxides [10,80,81] and nanoporous gold [82] are very effective in this reaction. Similarly, the AuNPs-PVP catalyst allowed for chemoselective hydrogenation of trans-2-butenal (crotonaldehyde), 2-methyl-2-propenal (methacrolein), 4-methyl-3-penten-2-one (mesityl oxide), and 3-methyl-3-penten-2-one in amide media, where enhanced colloidal stability and increased hydrogenation chemoselectivity were observed [77]. AuNPs of $7 \mathrm{~nm}$ synthesized in DMF yielded selective hydrogenation of crotonaldehyde with $93 \%$ conversion and selectivity in crotyl alcohol of $73 \%$; hydrogenation of mesityl oxide was obtained with a selectivity of only $58 \%$ into the corresponding allyl alcohol at a substrate/Au molar ratio of 200. Noteworthily, PtNPs and RuNPs are more active but substantially less chemoselective than the AuNPs catalyst. The AuNPsPVP catalyst was efficiently recycled by ultrafiltration through cross-linked polyimide membrane and reused many times showing good activity and selectivity in repeated hydrogenation runs.

\subsubsection{Reduction of Nitroarenes}

Reduction of nitroarenes (NAs) to the corresponding anilines (ANs) is a crucial reaction from an environmental and synthetic point of view. Actually, NAs are anthropogenic and toxic to living organisms, representing the major pollutant released in the environment during the post-industrialization era. In particular, nitrophenols (NPhs) contaminate the soil near former explosives or fabric factories and military plants; thus, current research efforts aim for their remediation [83]. From a synthetic point of view, aromatic amines are one of the largest groups of feedstocks used by the chemical industry produced by catalytic reduction of nitroaromatic compounds. Aniline, with a worldwide consumption of approximately 3 million tons in 2003, is produced on an industrial scale in a twostage process in which benzene is first nitrated and purified to yield nitrobenzene and then hydrogenated using a metal catalyst and hydrogen; this reaction presents a strong environmental impact. ANs are used to synthesize drugs, pesticides, and explosives; in addition, they are also the fundamental building blocks in polyurethane foams, rubber, azo dyes, photographic chemicals, and varnishes. 4-aminophenol (4-AP) finds applications as a photographic developer of black and white films, corrosion inhibitor, drying agent, and precursor for the manufacture of analgesic and antipyretic drugs (it is an important intermediate in the synthesis of paracetamol).

Considering that polymer supported AuNPs are typically applied under milder conditions, reductants stronger than dihydrogen are required (Table 2).

Table 2. Reduction of nitroarenes with $\mathrm{NaBH}_{4}$ promoted by polymer supported AuNPs.

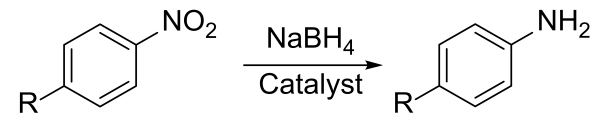

\begin{tabular}{cccccc}
\hline Catalyst & Substrate & Product & Conv. (\%) & Activity & Ref. \\
\hline $\begin{array}{c}\text { AuNPs-(PEO- } b- \\
\text { PAA) }\end{array}$ & $4-\mathrm{NP}$ & $4-\mathrm{AP}$ & $>99$ & TOF $=800 \mathrm{~mol} / \mathrm{mol}_{\text {cat }}$ & (Seo et al., 2013) [84] \\
\hline $\begin{array}{c}\text { AuNPs-(triazole } \\
\text { functionalized } \\
\text { PEG) }\end{array}$ & $4-\mathrm{NP}$ & $4-\mathrm{AP}$ & $>99$ & $\mathrm{k}_{\mathrm{app}}=5.2 \times 10^{-3} \mathrm{~s}^{-1}$ & (Zhao et al., 2013) [85] \\
\hline $\begin{array}{c}\text { AuNPs- } \\
\text { (PVP\&PMBAAm) }\end{array}$ & $4-\mathrm{NP}$ & $4-\mathrm{AP}$ & n.r. & $\mathrm{k}_{\mathrm{app}}=7.2 \times 10^{-2} \mathrm{~min}$ & (Xiao et al., 2012) [86] \\
\hline $\begin{array}{c}\text { AuNPs-(PS- } b- \\
\text { P4VP) }\end{array}$ & $4-\mathrm{NP}$ & $4-\mathrm{AP}$ & n.r. & $\mathrm{k}_{\mathrm{app}}=3.15 \times 10^{-3}$ & (Chen et al., 2008) [35] \\
\hline AuNPs-sPSB & nitrobenzene & aniline & $>99$ & $\mathrm{TOF}=2310 \mathrm{~mol} / \mathrm{mol}_{\mathrm{cat}} \mathrm{h}$ & (Noschese et al., 2016) [68] \\
\hline
\end{tabular}


Table 2. Cont.

\begin{tabular}{|c|c|c|c|c|c|}
\hline Catalyst & Substrate & Product & Conv. (\%) & Activity & Ref. \\
\hline AuNPs-PPI & 4-NP & 4-AP & $>99$ & $\mathrm{k}_{\mathrm{app}}=9.49 \times 10^{-3} \mathrm{~s}^{-1}$ & (Esumi et al., 2003) [87] \\
\hline AuNPs-PAMAM & $4-\mathrm{NP}$ & 4-AP & $>99$ & $\mathrm{k}_{\mathrm{app}}=3.70 \times 10^{-3} \mathrm{~s}^{-1}$ & (Hayakawa et al., 2003) [88] \\
\hline $\begin{array}{c}\text { AuNPs- } \\
\text { (PGMA@PAH) }\end{array}$ & $4-\mathrm{NP}$ & 4-AP & $>99$ & $\mathrm{k}_{\mathrm{app}}=1.97 \times 10^{-2} \mathrm{~s}^{-1}$ & (Li and Chen, 2013) [89] \\
\hline $\begin{array}{l}\text { AuNPs-(methyl- } \\
\text { imidazolium- } \\
\text { based ionic } \\
\text { polymer) }\end{array}$ & $4-\mathrm{NP}$ & $4-\mathrm{AP}$ & $>99$ & $k_{\mathrm{app}}=1.2 \times 10^{-3} \mathrm{~s}^{-1}$ & (Biondi et al., 2011) [78] \\
\hline AuNPs-PANI & $4-\mathrm{NP}$ & $4-\mathrm{AP}$ & $>99$ & $k_{\mathrm{app}}=11.7 \times 10^{-3} \mathrm{~s}^{-1}$ & (Han et al., 2010) [90] \\
\hline $\begin{array}{l}\text { AuNPs-(PEI\&PVA } \\
\text { nanofibers) }\end{array}$ & $4-\mathrm{NP}$ & $4-\mathrm{AP}$ & 72 & n.r. & (Fang et al., 2011) [91] \\
\hline $\begin{array}{c}\text { AuNPs- } \\
\text { (PANI\&PSS) }\end{array}$ & $4-\mathrm{NP}$ & $4-\mathrm{AP}$ & $>99$ & $k_{\mathrm{app}}=2.17 \times 10^{-2} \mathrm{~s}^{-1}$ & (Liu et al., 2014) [92] \\
\hline $\begin{array}{c}\text { AuNPs } \\
\text {-cyclodextrin }\end{array}$ & $4-\mathrm{NP}$ & 4-AP & $>99$ & $k_{\mathrm{app}}=4.65 \times 10^{-3} \mathrm{~s}^{-1}$ & (Huang et al., 2009) [93] \\
\hline $\begin{array}{c}\text { AuNPs- } \\
\text { (PEG\&PEI\&PCL) }\end{array}$ & $4-\mathrm{NP}$ & 4-AP & n.r. & $k_{\mathrm{app}}=0.370 \mathrm{~min}^{-1}$ & (Dai et al., 2015) [42] \\
\hline
\end{tabular}

The first report on the selective reduction of NAs to ANs using gold catalysts (AuNPs$\mathrm{TiO}_{2}$ and $\mathrm{Au}-\mathrm{Fe}_{2} \mathrm{O}_{3}$ ) and dihydrogen as reductant were reported by Corma et al., under harsh conditions $\left(\mathrm{P}_{\mathrm{H} 2}=15-25 \mathrm{~atm} ; \mathrm{T}=110-140{ }^{\circ} \mathrm{C}\right)[94,95] . \mathrm{NaBH}_{4}$ is essentially inefficient in the reduction of $-\mathrm{NO}_{2}$ to $-\mathrm{NH}_{2}$, but it becomes very effective in the presence of AuNPs. Reduction of 4-nitrophenol (4-NPh) with $\mathrm{NaBH}_{4}$ catalyzed by AuNPs is a "model catalytic reaction" where selectivity is an important reaction parameter because of the multistep nature of the reaction pathway. Actually, the reaction mechanism proposed by Haber comprises two pathways: the condensation and direct routes where a cascade reaction is involved. Moreover, the selective reduction of $\mathrm{NO}_{2}$ group in the presence of reducible functionalities at the aromatic ring of NAs is also challenging.

Seo et al., used double hydrophilic block copolymer (DHBC) poly(ethylene oxide)block-poly(acrylic acid) (PEO-b-PAA) as a template to stabilize AuNPs to be applied in 4-NPh reduction using $\mathrm{NaBH}_{4}$ [84]. The DHBC-templated AuNPs (AuNPs-DHBC) are stable for several months in water without any noticeable aggregation and provide enhanced catalytic activity by inner confined AuNPs in this solvent. The AuNPs-DHBC are highly effective in catalyzing the reduction of a series of NAs; remarkably, the turnover frequency in the case of 4-NPh reaches the value of $800 \mathrm{~h}^{-1}$, outperforming other previously reported AuNPs-based catalytic systems. The authors attributed the enhanced catalytic activity to the DHBC shell around AuNPs that templates the formation of spherical AuNPs; more importantly, it provides a confined inner reactor where reduction occurs. Another recent example was reported by Zhao et al., who synthesized icosahedral AuNPs stabilized by PEO end capped with triazole units where the protonated triazole stabilizer weakly coordinates the AuNP surface [85]. These AuNPs showed enhanced catalytic activity leading to nearly complete reduction of the substrate within $280 \mathrm{~s}$ at $25^{\circ} \mathrm{C}\left(4-\mathrm{NPh} / \mathrm{NaBH}_{4}\right.$ molar ratio of 1:100) with a kinetic constant of $k=5.2 \times 10^{-3} \mathrm{~s}^{-1}$ under pseudo first order kinetic condition.

AuNPs stabilized with interpenetrating polymers consisting of P4VP and poly $(\mathrm{N}, \mathrm{N}-$ methylenebisacrylamide (PMBAAm) produced hybrid nanogel with both a $\mathrm{pH}$ - modulated catalytic activity and anti-aggregation properties [86]. Noteworthily, the AuNPs(PVP\&PMBAAm) showed a core-shell architecture where the shell is permeable to both reactants and products and the mass-transfer limitations is avoided to maximize the reaction rates. The high porosity of the gel layer in the AuNPs-PVP hybrid nanogels was found crucial for the catalytic applications. The $\mathrm{pH}$-responsive swelling-deswelling transition behavior does confirm the highly porous nature of the gel layer. At $\mathrm{pH}>8.0$, the size of the hybrid nanogels remains nearly a constant; at $\mathrm{pH}$ of 8.0 , the size gradually increases until 
$\mathrm{pH}$ of 6.0, where the hybrid nanogels reach a maximum swelling. This swelling-deswelling $\mathrm{pH}$ dependent transition is close to the hydrophilic-hydrophobic transition of the PVP film at $\mathrm{pH}$ of about 7.5; at higher $\mathrm{pH}$ values, the $\mathrm{P} 4 \mathrm{VP}$ film is relatively hydrophobic, and at lower $\mathrm{pH}$ values it becomes more hydrophilic. The kinetics is of pseudo first order with regard to both the reactants in the range of $\mathrm{pH}$ from 5.0 to 9.3.

Chen, Shi, and co-workers synthesized core-micelle-supported gold composites with a polystyrene core and a poly(4-vinyl pyridine) / Au shell (AuNPs-(PS-b-P4VP)) using $\mathrm{NaBH}_{4}$ as reductant of $\mathrm{HAuCl}_{4}$ acidic aqueous solution ( $\left.\mathrm{pH} \sim 2\right)$. The morphological control in the catalyst synthesis is driven by a self-assembly process of the PS- $b$-P4VP block copolymer in water solution [35]. Samples were synthesized at variance of $\mathrm{Au} / \mathrm{P} 4 \mathrm{VP}$ molar ratio of 1:3 (C-1), 1:5 (C-2), and 1:7 (C-3); the increase of the molar ratio leads to an increase of number of AuNPs but not of their size. The (C-1)-(C-3) catalysts were thus tested in 4-NPh reduction and the kinetic plots provided $k_{\text {app }}$ values of $3.15 \times 10^{-3}, 9.63 \times 10^{-4}$, and 3.66 $\times 10^{-5} \mathrm{~s}^{-1}$, respectively. These authors suggested that the catalytic activity is proportional to the gold loading but the morphology of the polymer support plays an important role in catalysis; at high P4VP content, the accessibility of the reagent to the AuNPs surface is limited by competitive coordination of the P4VP units.

AuNPs embedded in a crystalline porous polymer matrix consisting of syndiotactic polystyrene-co-cis-1,4- polybutadiene multi-block copolymer (AuNPs-sPSB) were synthesized at variance of four different crystalline phases of the support, namely, AuNPs-( $\beta$ )sPSB, AuNPs- $(\gamma)$ sPSB, AuNPs- $(\delta)$ sPSB, and AuNPs- $(\varepsilon)$ sPSB, to assess the role of the crystalline phases $\beta, \gamma, \delta$, and $\varepsilon$ in the cascade reaction and to highlight some features of the reaction mechanism [68]. The AuNPs- $(\beta)$ sPSB and AuNPs- $(\gamma)$ sPSB catalysts show low specific surface area and porosity, as expected from the packing of the polymer chains in the crystalline phase, whereas AuNPs- $(\delta)$ sPSB and AuNPs- $(\varepsilon)$ sPSB exhibit nanovoids and nanochannels that can host both NB and the aromatic reaction intermediates in the crystalline phase. The catalytic runs were performed in methanol to avoid modification of the crystalline form of the polymer matrix in the course of the reaction. AuNPs-( $\delta$ )sPSB and AuNPs$(\varepsilon)$ sPSB produce AN with TOF values in the range of the most active gold catalysts (2310 $\left.\mathrm{mol} / \mathrm{mol}_{\mathrm{cat}} \mathrm{h}\right)$, whereas AuNPs-( $\left.\beta\right)$ sPSB and AuNPs- $(\gamma)$ sPSB yielded azoxybenzene (AOB) and azobenzene $(\mathrm{AB})$ as the main reduction products. The reaction profiles show that the formation of $\mathrm{AOB}$ and $\mathrm{AB}$ is fast, also outside of the polymer phase, and their diffusion through the polymeric support allows for definitive reduction into AN with a pseudo-1st order reaction (see Scheme 1). When gold catalytic sites are immediately accessible to the reactants, and the prevalence of the direct route of the Haber's mechanism leading to the reduction of arylhydroxylamine into AN has been proposed. On the contrary, the accumulation of the primary reaction intermediates, nitrosobenzene and arylhydroxylamine, promotes the condensation route that in many cases produces the partial reduction of NB into $\mathrm{AOB}$ and $\mathrm{AB}$. This study allows one to address the following conclusions. Both the reaction routes proposed in the Haber mechanism are possible with heterogeneous gold catalysts; the condensation route is favored when the reduction of primary products, such as nitrosobenzene and arylhydroxylamine, is slow and these intermediates accumulate on the gold surface; on the contrary, very active catalysts lead to the fast conversion into AN in a straightforward way $[68,96,97]$.

The first example of dendrimer-encapsulated AuNPs (AuNPs-DENs) applied to 4-NPh reduction was reported in 2002 by Esumi's group $[87,88]$. Poly (amidoammine) dendrimers (PAMAM) of 3.0-5.0 generation and poly(propyleneimine)dendrimers (PPI) of 3.0-4.0 generation were used to stabilize the AuNPs obtained by laser irradiation. A dendrimerconcentration-dependent factor was observed in the reduction of 4-NPh using $\mathrm{NaBH}_{4}$ as reductant; namely, the concentration of the dendrimers in the AuNPs nanocomposites is lower and the catalytic activity in 4-NP reduction is higher, independently of the dendrimer generation. The rate constants for AuNPs-PPI $\left(k_{a p p}=9.01-9.49 \times 10^{-3} \mathrm{~s}^{-1}\right)$ are considerably higher than those for AuNPs-PAMAM $\left(k_{\mathrm{app}}=2.13-3.70 \times 10^{-3} \mathrm{~s}^{-1}\right)$ because of different diffusion rate of $4-\mathrm{NPh}$ through the dendrimer monolayer. 
a)
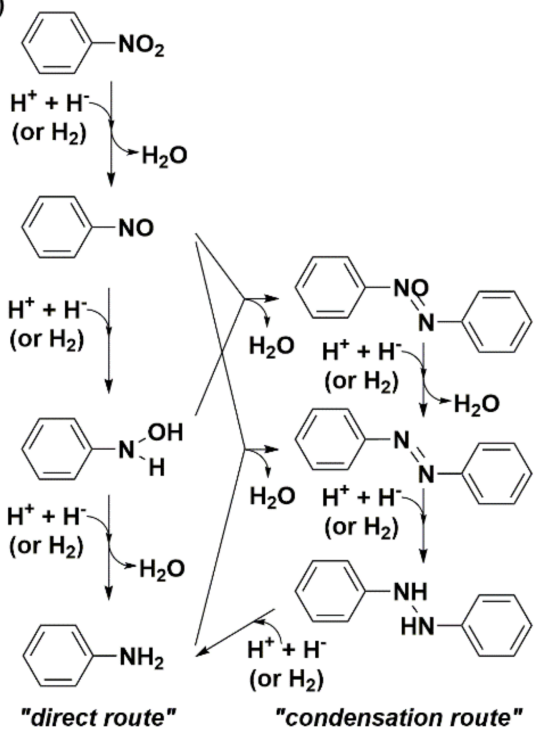

b)

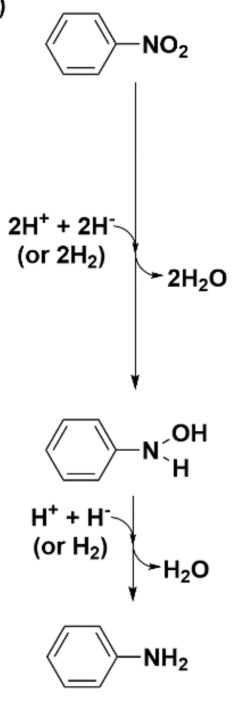

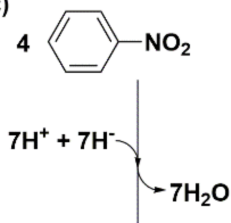

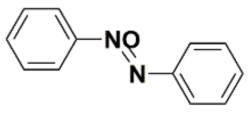

$+$

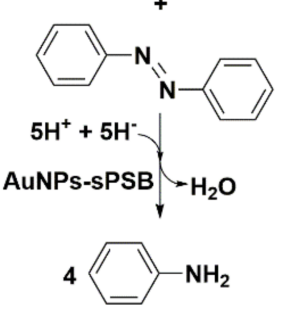

Scheme 1. Mechanisms for nitroarene reduction catalyzed by AuNPs: (a) Haber's general mechanism; (b) conventional route over AuNPs; (c) route over AuNPs-sPSB (see reference [68]). Adapted with permission from reference [68].

Chen's group designed a raspberry-like polymer support consisting of poly(glycidyl methacrylate) (PGMA) sub-microspheres reactive with many functional groups such as hydroxyl, carbonyl, and amine moieties, via ring-opening reactions [89]. Negatively charged PGMA spheres were modified with a layer of weakly hydrophobic cationic polyelectrolyte film, poly(allylamine hydrochloride) (PAH), and used as AuNPs coating to obtain the corresponding gold catalyst (AuNPs-(PGMA@PAH)). The catalytic reduction of 4-NP with an excess amount of $\mathrm{NaBH}_{4}$ exhibited excellent catalytic activity with TOF of $250 \mathrm{~mol}_{4-\mathrm{NP}}$ $x$ mol $_{\mathrm{cat}^{-1}} \mathrm{~s}^{-1}$ and the full conversion of $4-\mathrm{NP}(0.125 \mathrm{mmol})$ within $76 \mathrm{~s}$. The catalytic activity of the composite particles was found to decrease as the $\mathrm{pH}$ value of the reaction solution was increased $(\mathrm{pH}=3-11)$ as a result of the variation of the PAH charge and conformation. In a further study, the same authors investigated in detail kinetics of 4-NP reduction catalyzed by AuNPs-(PGMA@PAH)) [89]. The increase of the sub-microsphere size at $\mathrm{pH}$ of 3 will increase the number of gold atoms accessible to the reagent leading to highest $k_{\text {app }}$ value of $1.97 \times 10^{-2} \mathrm{~s}^{-1}$; the reaction order of 4-NP is closely correlated with the surface coverage amount of the coated gold nanoparticles on the modified polymer spheres. More importantly, such an enhanced reaction activity could be tuned at variance of the PAH concentration, the volume ratio of the polymer spheres to the AuNPs, and the $\mathrm{pH}$ value of the solution. Last but not least, a shorter induction period $(<30 \mathrm{~s})$ was found and ascribed to the catalytic-induced reconstruction of the surface of the heterogeneous composite catalyst.

Ring opening polymerization of norbornene monomers functionalized with methylimidazolium group yielded a water-soluble polymer support for AuNPs [78]. This catalyst showed a $k_{\text {app }}$ of $1.2 \times 10^{-3} \mathrm{~s}^{-1}$ at molar concentration $0.048 \mathrm{mM}$ of 4-NP.

Polyaniline (PANI) nanofibers composites with AuNPs of different sizes (2nm and $10 \mathrm{~nm}$ ) were synthesized using PANI as both reducing agent of the gold precursor and as support [90]. AuNPs-PANI nanofiber composites served as effective recyclable catalyst to promote the 4-NP reduction in the presence of $\mathrm{NaBH}_{4}$, where the AuNPs size is found to play a determining role in catalysis. The reaction follows a pseudo first order kinetics with respect to NPs, but an induction time of 4 min was observed with bigger AuNPs; the reaction is complete in $10 \mathrm{~min}$ with both the catalysts. Disappointingly, a decrease of the catalytic activity was monitored during the recycling experiments.

AuNPs immobilized within PEI/PVA nanofibers showed good catalytic activity in 4-NP reduction using $\mathrm{NaBH}_{4}$ as reductant; the reaction is complete in 36 min without 
showing induction time. Noteworthily, the catalyst is thermally stable in the range of temperature $50-150{ }^{\circ} \mathrm{C}$ and the heating treatment does not compromise the catalytic activity of the nanoparticles. AuNPs immobilized within PEI/PVA cast films showed a lower catalytic activity where the efficiency could only reach a conversion value of $72 \%$ at the same time point of $36 \mathrm{~min}$ [91].

Polyaniline/poly(sodium 4-styrenesulfonate)-stabilized gold nanoparticles (AuNPs(PANI-PSS)) are efficient, versatile catalysts in 4-NP reduction. The nanocomposites exhibit excellent dispersibility and stability in water in a wide range of $\mathrm{pH} 1-12$. The AuNPs-PANI also exhibited an apparent rate constant of only $2.10 \times 10^{-3} \mathrm{~s}^{-1}$, whereas the reaction with AuNPs-(PANI-PSS) is compete in $160 \mathrm{~s}$. A gradual decrease of the catalytic activity was observed in consecutive runs and was attributed to the complex recovery procedure by dialysis [92].

AuNPs supported by block copolymers were efficiently used by Wang et al., for the reduction of 4-NP to 4-AP [42]. ABC triblock copolymers poly(ethylene glycol)poly(ethylenimine)-poly( $\varepsilon$-caprolactone) (PEG-PEI-PCL) compared with AB diblock copolymers PEG-PEI were more effective at enhancing stability and catalytic activity of the AuNPs. The kinetic reaction rate constants for PEG-PEI-PCL- and for PEG-PEI-stabilized AuNPs were, respectively, $0.370 \mathrm{~min}^{-1}$ and $0.193 \mathrm{~min}^{-1}$.

AuNPs stabilized by cyclodextrin, collagen, or natural polymers were also synthesized and applied in 4-NP reduction without noteworthy notations [93].

\subsection{Selective Oxidations}

Most of the oxidation reactions are carried out in industry using toxic reagents and stoichiometric reaction involving large excess of the oxidant. As an example, alcohol oxidation is carried out using chromic oxides such as the Jones reagent, pyridinium chlorochromate, and pyridinium dichromate. Sustainable homogenous catalysts based on TEMPO in the presence of excess bleach ( $\mathrm{NaOCl}$ ) (oxoammonium-catalyzed oxidation) have been also applied in these reactions. All these reactions produce voluminous amounts of wastes typically comprising toxic metals or large volume fraction of useless salts [98,99].

Catalysis by supported AuNPs has been mainly addressed in the last decades to catalytic oxidation of organic compounds such as alcohols, polyols, and carbonyl compounds from renewable resources using environmentally friendly oxidant such as dioxygen (possibly air) or hydrogen peroxide [18,100-108]. Oxygen gets chemically adsorbed on nanogold [109-112], and thus it provides green processes based on the use of stable, selective, and non-toxic heterogeneous catalysts with air or $\mathrm{O}_{2}$ as eco-friendly oxidant $[107,113,114]$.

Cross-linked polymers have been adopted as supports because of their large availability, ease of separation, and enhanced stabilization of the AuNPs, which make them popular support, especially for solution phase oxidation reactions; examples include commercial and synthetic polymers such as poly(ethylene glycol) (PEG), polystyrene (PS), polysiloxane, polyisobutylene, P4VP, modified PS, sPSB, and dendrimers [23].

\subsubsection{Alcohol Oxidation}

Selective oxidation of alcohols is one of the most important transformations in organic synthesis, since the resulting carbonyl compounds possess higher energy and reactivity to allow many kinds of carbon-carbon bond-forming and other transforming reactions [108,115]. Alcohol oxidation using molecular oxygen catalyzed by reusable heterogeneous catalysts under mild conditions is desired from the viewpoints of atom economy and energy efficiency (Table 3) [116]. Aerobic oxidation of primary alcohols to form aldehydes, which are valuable intermediates, is challenging because it suffers of the strong limitation from overoxidation to carboxylic acids [117].

Following the pioneering studies on the oxidation of glucose [118] and glycerol [119] catalyzed by AuNPs supported on carbon (AuNPs-C), Tsukuda reported the aerobic oxidation of benzyl alcohol promoted by monodisperse AuNPs-PVP; the reaction was 
carried out using water as solvent and a trifold excess of $\mathrm{K}_{2} \mathrm{CO}_{3}$ as co-catalyst [120]. Kinetic measurements showed that the smaller nanoparticles $(1.3 \mathrm{~nm})$ exhibit superior catalytic activity than the larger ones $(9.5 \mathrm{~nm})$ and that the AuNPs are more active of one order of magnitude than PdNPs in this reaction. Concerning the reaction mechanism, these authors calculated the energetic barrier of $20 \mathrm{KJ} \mathrm{mol}^{-1}$ and proposed that the cleavage of the $\mathrm{C}-\mathrm{H}$ bond at the benzylic position is the rate determining step, as assessed by the large kinetic isotope effect (KIE) observed in the oxidation of $p-\mathrm{HOC}_{6} \mathrm{H}_{4} \mathrm{CD}_{2} \mathrm{OH}\left(k_{\mathrm{H}} / k_{\mathrm{D}}=74\right)$. However, the product selectivity was in favor of benzoic acid instead of benzaldehyde, which remains the most challenging reaction product to be obtained; the main drawback of this catalyst is its recovery and reuse from the reaction solution. The $\mathrm{X}$-ray photoelectron and Fourier transform infrared (FT-IR) spectroscopic analysis of the Au clusters after treatment with $\mathrm{CO}$ provided insight into the reaction mechanism. The electron donation from the nitrogen donor atom of PVP to the surface of the AuNPs produces a negatively charged gold cluster core that thus generates superoxo-or peroxo-like species as a result of the interaction of the $\operatorname{LUMO}\left(\pi^{*}\right)$ of $\mathrm{O}_{2}$ with the Au core (see Scheme 2). The position of the hydroxyl group onto the phenyl ring of benzyl alcohol has a remarkable effect on the selectivity of the reaction. When located at the ortho-position, $o-\mathrm{HOC}_{6} \mathrm{H}_{4} \mathrm{CHO}$ is the main reaction product, whereas in meta position a mixture of aldehyde and acid was obtained; finally, $p-\mathrm{HOC}_{6} \mathrm{H}_{4} \mathrm{CH}_{2} \mathrm{OH}$ leads to the selective formation of $p$-hydroxyl-benzaldehyde in $91 \%$ yield.

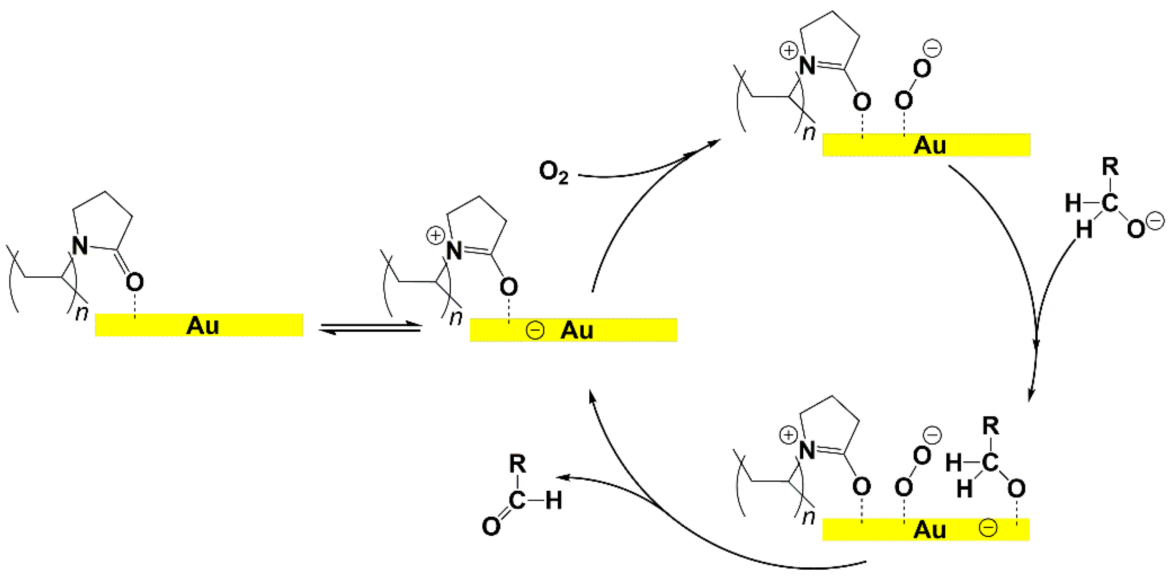

Scheme 2. Mechanism of alcohol oxidation catalyzed by AuNPs-PVP proposed by Tsukuda et al., (see reference [120]).

Table 3. Aerobic alcohol oxidations promoted by polymer supported AuNPs.

$\begin{gathered}\text { Catalyst/Co- } \\ \text { Catalyst }\end{gathered}$
(Au\&Pd)NPs-
$\mathrm{PVP}$


Table 3. Cont

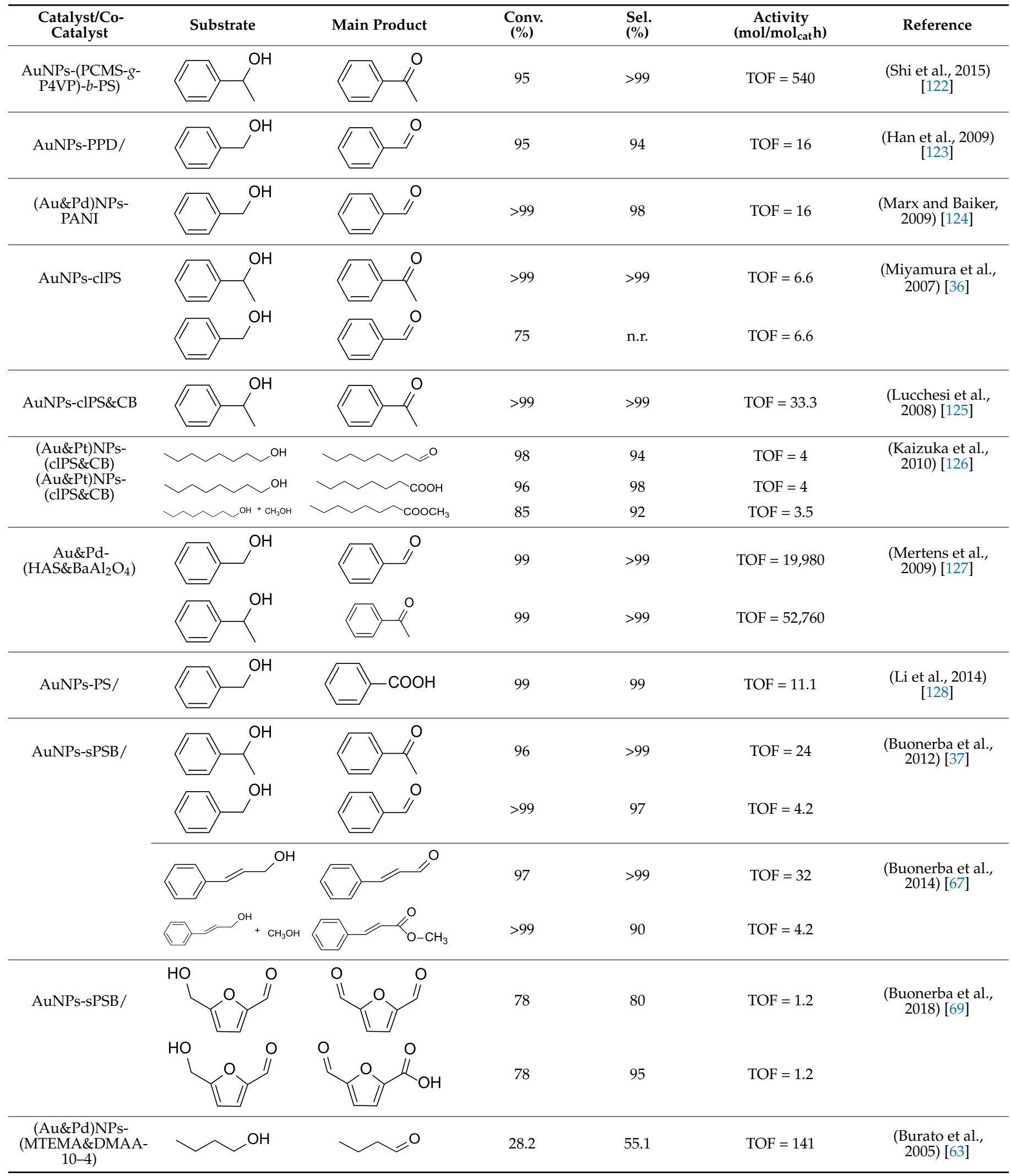

To improve catalyst recyclability Dyson and co-workers discovered that AuNPs stabilized by PVP functionalized with carboxylic groups can be separated from the reaction mixture by lowering the $\mathrm{pH}$ of the solution that caused the AuNPs precipitation [129]. 
The catalyst yields pseudo homogenous aqueous solutions at $\mathrm{pH}>2.5$, where the highest catalytic activity is observed, whereas it precipitates at $\mathrm{pH}<2.4$; however, the selectivity is still high in favor of benzoic acid as main reaction product.

The (Au\&Pd)-PVP core-shell nanocatalyst was also applied in the selective aerobic oxidation of crotyl alcohol to crotonaldehyde [121]. Different PVP-stabilized Au\&Pd coreshell catalysts were prepared using AuNPs as seed, followed by the sequential addition of $\mathrm{Au}$ and $\mathrm{Pd}$ precursors and co-reduction; the size of the resulting (Au\&Pd)-NPs is in the range of 3-10 nm. These authors showed that the Pd-rich surfaces behave as excellent catalysts at room temperature in the aerobic oxidation of crotyl alcohol with selectivity of $88 \%$ and TON of $306 \mathrm{~mol} / \mathrm{mol}_{\text {cat }}$; under the same reaction conditions, the coreduced Au\&Pd catalyst showed TON value of only $40 \mathrm{~mol} / \mathrm{mol}_{\text {cat }}$. Mechanism exploration suggested a redox cycle of $\mathrm{Pd}(\mathrm{II})$ and $\mathrm{Pd}(0)$ where the $\beta$-H elimination pathway could not be ruled out completely.

Zang and co-workers developed a new kind of brush block terpolymer, namely, [poly(p-chloromethylstyrene)-g-poly(4-vinylpyridine)]- $b$-polystyrene,(PCMS- $g$-P4VP)- $b$-PS, used as a support for the stabilization of AuNPs. The immobilized AuNPs $(1 \mathrm{~nm})$ exhibited remarkable activity in the aerobic oxidation of 1-phenyl ethanol to produce acetophenone as main product with $96 \%$ yield in $6 \mathrm{~h}$ [122].

AuNPs of $5 \mathrm{~nm}$ embedded in poly(o-phenylenediamine) (PPD) submicrosphere of $700 \mathrm{~nm}$ were obtained by impregnation of the polymer support with $\mathrm{HAuCl}_{4}$ without additional reducing agents; the amino groups and $\pi$-electrons of the aromatic rings act as both reducing and stabilizing agents [123]. TEM images showed AuNPs uniformly deposited on the surfaces of PPD submicrosphere. This catalyst showed good catalytic activity and selectivity in benzyl alcohol oxidation to benzaldehyde in water.

PANI are conducting polymers used in the synthesis of mono and bimetallic gold nanoparticles and act as a charge density donor producing enhanced catalytic activity of the AuNPs [124]. The size of the mono and bimetallic particles was controlled in a narrow size range (2.4-3.7 nm) using a colloidal preparation route. The authors concluded that if the Pd loading in bimetallic nanoparticles is increased from 1 to $9 \mathrm{~mol} \%$, a significant increase in the catalytic activity will be observed with $100 \%$ conversion of benzyl alcohol and $98 \%$ selectivity for benzaldehyde at $100{ }^{\circ} \mathrm{C}$.

Kobayashi et al., reported that AuNPs-clPS showed excellent catalytic activity in alcohol oxidation at room temperature using $\mathrm{O}_{2}$ at atmospheric pressure and $\mathrm{KOH}$ as co-catalyst $[36,125,130]$. The gold catalyst is fully reusable for at least five time without loss of catalytic activity. The best results are achieved in oxidation runs carried out in binary solvent like toluene/water and benzotrifluoride/water to increase $\mathrm{O}_{2}$ solubility in the reaction media. The catalyst was preliminary screened in the oxidation of a variety of alcohols; good conversion $(>75 \%)$ and selectivity towards the corresponding aldehydes were obtained in all considered cases [36]. The same group used integrated carbon black (CB) in the polymer support (PS\&CB) to increase the gold loading in polystyrene resin; the size of the AuNPs did not increase much as the gold loading was increased from $5 \mathrm{wt} \%$ to $20 \mathrm{wt} \%$. Interestingly, the bimetallic catalyst (Au\&Pt)NPs-(clPS\&CB) allows alcohol oxidation under neutral condition, thus avoiding the use of an external base [124]. The (Au\&Pt)NPs-(clPS\&CB) oxidized 1octanol to octanal in excellent yield and selectivity; 1-octanoic acid was found as minor reaction product. In the presence of $\mathrm{K}_{2} \mathrm{CO}_{3}$, the major product was 1-octanoic acid, whereas overoxidation of 1-octanal to 1-octanoic acid was suppressed under neutral conditions. In a methanol/water solvent system, oxidation of 1-octanol was suppressed and a small amount of methyl 1-octanoate was obtained [126,130]. Primary aliphatic alcohols and benzyl alcohols were smoothly converted to the corresponding aldehydes in high yields $(>94 \%)$ and selectivity. When methanol was added in the reaction mixture, the corresponding methyl-esters were obtained in excellent yields (see also Section 3.2.4). TEM and ICP analysis of the bimetallic catalyst showed that formation of a metal alloy at gold to platinum molar ratio of 1:1.

The mechanism of the oxidation of alcohols promoted by AuNPs has been extensively studied [116,131-133]. Garcia [132] and Kobayashi [133] independently suggested a $\beta$ - 
elimination of hydride from the alcohol by the gold as key step in the oxidation (see Scheme 3). In detail, Kobayashi proposed that the role of the oxygen was limited to the restoration of the catalytic metal surface.

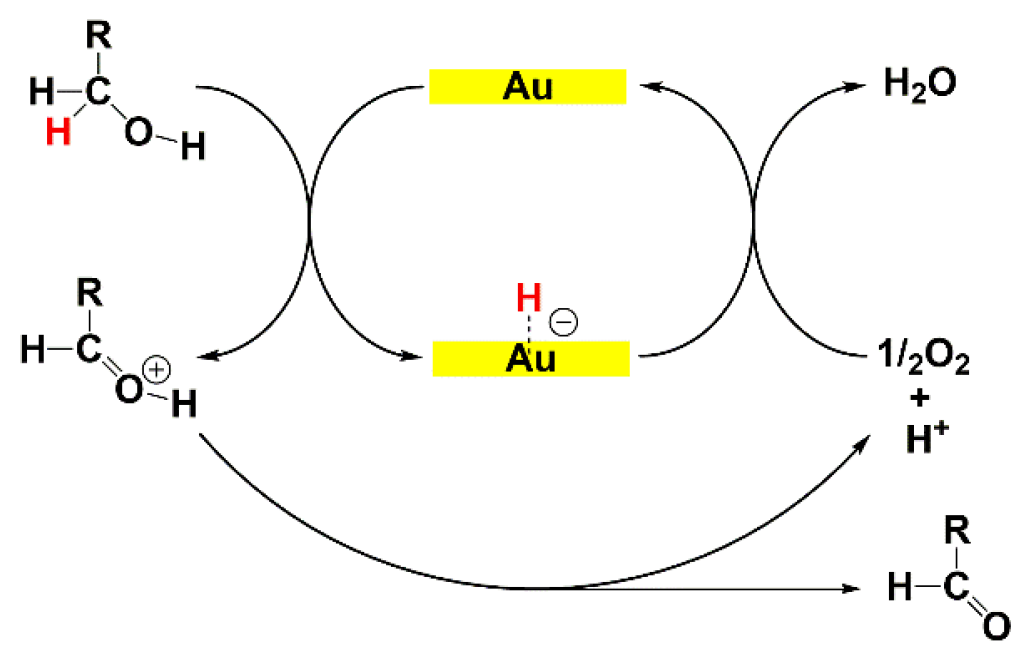

Scheme 3. Mechanism of alcohol oxidation: $\beta$-hydride migration from the alcohol to the surface of the AuNPs and dioxygen reduction for the regeneration of the catalytic site.

De Vos reported that the introduction of a base into the inorganic support can readily increase the catalytic activity of the Au\&Pd catalyst in alcohol oxidation reactions. The Au\&Pd-(HAS\& $\left.\mathrm{BaAl}_{2} \mathrm{O}_{4}\right)$ catalyst was very efficient in benzyl and allyl alcohols oxidation, producing corresponding ketones or aldehydes with very high TOF and 99\% selectivity without using additional bases [127].

Li et al., reported that the AuNPs-PS catalyst consisting of PS microsphere obtained by conventional dispersion polymerization is highly active in benzyl alcohol oxidation using $\mathrm{K}_{2} \mathrm{CO}_{3}$ as base in aqueous medium at atmospheric pressure of $\mathrm{O}_{2}$ [128]. The TEM analysis showed AuNPs of $3.5 \mathrm{~nm}, 9.5 \mathrm{~nm}$, and $6.7 \mathrm{~nm}$ homogenously dispersed on the surface of PS microspheres. This composite showed good recyclability and was reused several times without significant loss of activity; however, the selectivity is still high in benzoic acid vs. benzaldehyde.

The AuNPs-sPSB catalyst was successfully applied in the oxidation of primary and secondary alcohols using $\mathrm{O}_{2}$ as oxidant in organic-water mixture of solvent [37]. 1Phenylethanol was oxidized to acetophenone in high yields $(96 \%)$ in $1 \mathrm{~h}$ at $358^{\circ} \mathrm{C}$, whereas benzyl alcohol was quantitatively oxidized to benzaldehyde with a selectivity of $97 \%$ in $6 \mathrm{~h}$. A range of allyl and benzyl alcohols were oxidized to the corresponding aldehydes with excellent yield and selectivity, whereas alkyl alcohols are inert under the same conditions. The good performances were attributed to the presence of naked AuNPs embedded in the physically crosslinked and nanoporous polymer support that ensures facile and selective accessibility of the reactants to the Au catalyst (see Section 3.1.3.). The kinetic investigation of the reaction mechanism highlighted first-order kinetics for the aromatic reactants showing high affinity and fast diffusion through the polystyrenic matrix; oxidation of the aliphatic alcohol is sluggish and controlled by diffusion likely through the amorphous phase of the polymer support. Aiming to apply this chemistry to the synthesis of fine chemicals from renewable resources, the AuNPs-sPSB catalyst was tested in HMF oxidation. The AuNPs-sPSB catalyst is highly effective and selective in addressing the conversion of HMF into the desired oxidation product [69]. Compared to commercial gold-catalysts such as AuNPs-TiO 2 and AuNPs-CB, the AuNPs-sPSB catalyst offers the possibility of a fine control of the reaction product by a simple tuning of the reaction parameters. HMF oxidation to 2,4-diformyl furan (DFF) was efficiently obtained under anhydrous conditions, moderate reaction temperature $\left(40-80{ }^{\circ} \mathrm{C}\right)$, low base content (1 equiv.), and an oxygen pressure of 1.5 MPa. The switch in selectivity toward 2-formyl-4-furan carboxylic acid 
(FFCA) occurs under more severe conditions $\left(110{ }^{\circ} \mathrm{C}, 2.5-3.5 \mathrm{MPa}\right.$ and/or base excess) and is favored by water resulting from the first oxidation step to DFF, which produces the gem-diol intermediate.

Cross-linked copolymers of $\mathrm{N}, \mathrm{N}$-dimethylacrylamide (DMAA), 2-(methylthio)ethyl methacrylate (MTEMA), and $N, N$-dimethylenebisacrylamide were used as supports for PdNPs and AuNPs via extraction of Pd(II) and $\mathrm{Au}(\mathrm{III})$ from aqueous solution followed by metal reduction with $\mathrm{NaBH}_{4}$. These catalysts exhibited good activity in the oxidation of 1-butanol to 1-butaldehyde; the selectivity to butaldehyde reached $40-70 \%$ at $20-40 \%$ 1-butanol conversion [63].

Kobayashi et al., designed a microchannel flow reactor by immobilizing AuNPs and bimetallic (Au\&Pd)NPs in a polysiloxane capillary column. Benzyl alcohols with different structures were oxidized into the corresponding aldehydes/ketones with $89-99 \%$ yield at $50-70{ }^{\circ} \mathrm{C}[134]$.

Tsukuda et al., developed highly stable and durable AuNPs of $4 \mathrm{~nm}$ in water phase using star like thermo sensitive polyvinyl vinyl ether synthesized by living polymerization of 2-2(ethoxy) ethoxy ethyl vinyl ether. The resulting clusters efficiently catalyzed aerobic oxidation of benzyl alcohol to benzoic acid with $99 \%$ of selectivity and a variety of alcohol derivatives; these authors suggested that the Au NPs are in the hydrophobic layers [135].

Block copolymers having segregated hydrophilic/hydrophilic polymer domains can provide better stabilization and dispersion of the MNPs. Kawanami et al., synthesized AuNPs-(poly(ethylene oxide)-poly(propylene oxide)-poly(ethylene oxide)) (AuNPs-PEOPPO-PEO) where the block copolymer acted as both reductant and stabilizer in the synthetic procedure. Spherical AuNPs of 4-12 $\mathrm{nm}$ (7.3 nm as average value) were obtained and tested in alcohol oxidation. High conversion was monitored in benzyl alcohol oxidation $(99 \%)$, but the selectivity in benzaldehyde was only of $8 \%$, whereas the main side products were benzoic acid and benzyl benzoate [136].

Immobilized AuNPs in a polysiloxane-coated capillary column $(50 \mathrm{~cm}$ length; $250 \mathrm{~mm}$ i.d.) with inner lining of $50 \%$ phenyl and $50 \% n$-cyanopropyl functionalities $(0.25 \mathrm{~mm}$ of thickness) led to $99 \%$ conversion of 1-phenyl ethanol into acetophenone using DCM eluent and $\mathrm{K}_{2} \mathrm{CO}_{3}$ as base; the results were independent of the flow rate of the $\mathrm{K}_{2} \mathrm{CO}_{3}$ solution and oxygen concentration. The oxidation of a variety of alcohols such as benzylic, aliphatic, and allylic alcohols led to high conversion and excellent selectivity with good recyclability of the catalyst [134].

\subsubsection{Polyols Oxidation}

Some examples of polyol oxidation are shown in Table 4.

Table 4. Aerobic oxidations of polyols promoted by polymer supported AuNPs.

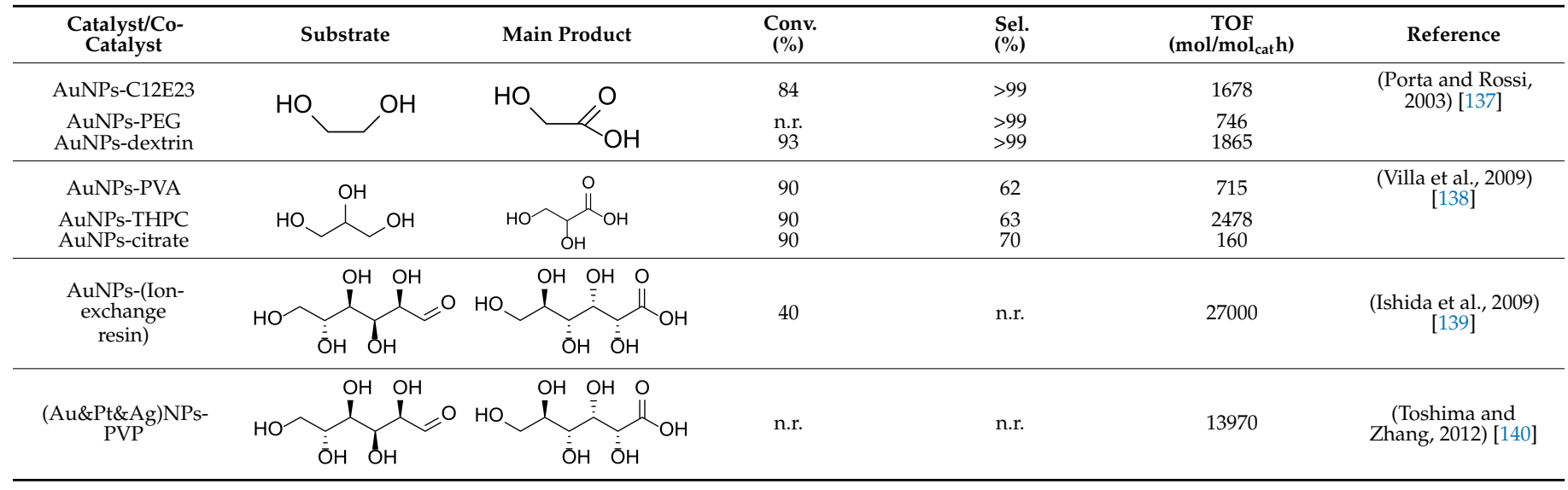

The pioneering works in polyols oxidation described the selective oxidation of ethylene glycol to sodium ethylene glycolate using AuNPs-C [137] or alumina (AuNPs- 
$\mathrm{Al}_{2} \mathrm{O}_{3}$ ) [141] using $\mathrm{NaOH}$ as external base (Table 4). The AuNPs-C catalyst was prepared by dipping activated carbon with the prefabricated Au colloid in the presence of protecting agents such as the long chain compound poly(oxyethylene(23)lauryl ether (C12E23), the polymer poly(bis(2-chloroethyl)ether-alt-1,3-bis(3-(dimethylamino)propyl)urea), the poly quaternary salt obtained by reaction of PEG with the bisphenol A diglycidyl ether (PEU), and a polysaccharide (dextrin). After optimization of the experimental conditions, the polymer-protected AuNPs-C and AuNPs-dextrin catalysts exhibited the best performances leading to a conversion of ethylene glycol of $~ 80 \%$ [137].

AuNPs stabilized with poly(vinyl alcohol) (PVA), tetrakis-hydroxypropylphosphonium chloride (THPC), and citrate (Cy) were tested in glycerol oxidation in the presence of $\mathrm{NaOH}$ as base $(\mathrm{NaOH} /$ glycerol molar ratio $4: 1)$ and $\mathrm{O}_{2}$ as oxidant $(300 \mathrm{KPa})$ at $50{ }^{\circ} \mathrm{C}$ to establish as the type of interaction (steric vs. electrostatic) of the support with the AuNPs could affect activity and selectivity of the catalyst [138]. The TOF value increases in the

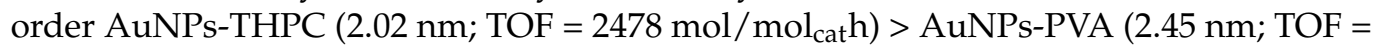
$\left.715 \mathrm{~mol} / \mathrm{mol}_{\text {cat }} \mathrm{h}\right)>$ AuNPs-Cy $\left(10 \mathrm{~nm}\right.$; TOF $\left.=160 \mathrm{~mol} / \mathrm{mol}_{\text {cat }} \mathrm{h}\right)$ suggested higher accessibility of the reactant to the catalytic sites in the first case. The highest selectivity $(\sim 70 \%)$ in glyceric acid/sodium glycerate was obtained with the Cy protected AuNPs, whereas AuNPs-THPC and AuNPs-PVA exhibited higher level of overoxidation leading to tartronic acid and glyceric acid.

Haruta et al., prepared a series of ion-exchange resin-supported AuNPs by reducing $\mathrm{HAuCl}_{4}$ with $\mathrm{NaBH}_{4}$ or with the amine/ammonium groups of the polymer support to yield catalysts with weakly acidic to strongly basic polymer supports; the gold catalysts were thus tested in glucose oxidation [139]. The strongly basic anion-exchange resins furnished the best catalyst performance with a TOF of $27,000 \mathrm{~mol} / \mathrm{mol}_{\mathrm{cat}} \mathrm{h}$ at $60{ }^{\circ} \mathrm{C}$ and $\mathrm{pH} 9.5$ in the presence of $\mathrm{NaOH}$; the selectivity was in favor of gluconic acid and sodium gluconate.

Recently, Toshima et al., developed a PVP-stabilized Au\&Pt\&Ag trimetallic nanocluster $(1.5 \mathrm{~nm})$ to be applied in aerobic oxidation of glucose [140]. The nanoparticles with Au:Pt:Ag molar ratio of 7:2:1 yielded the best results in water, at $60{ }^{\circ} \mathrm{C}$ and $\mathrm{NaOH}(\mathrm{pH}$ of 9.5), leading to a TOF value of $13,970 \mathrm{~mol} / \mathrm{mol}_{\text {cat }}$ h and high selectivity in gluconic acid/sodium gluconate. The excellent catalytic activity was attributed to the electronic charge transfer from $\mathrm{Ag}$ (or Pt) to Au.

Polymeric supports consisting of poly(diallyldimethylammonium chloride), chitosan [142], poly(2,2-trimethyl ammonium methylmetha chloride), polyvinyl alcohol, and ethylene imine were also explored but gave poor results.

\subsubsection{Amine Oxidation to Imine}

Imines are highly versatile synthetic intermediates for $\mathrm{C}-\mathrm{C}$ bond forming reactions, typically prepared by the addition of amines to carbonyl compounds. Catalytic oxidation of $\mathrm{N}$-alkyl amine into ketimine using $\mathrm{O}_{2}$ as oxidant is an attractive methodology for a green and economic approach to these target molecules (Scheme 4) [143].

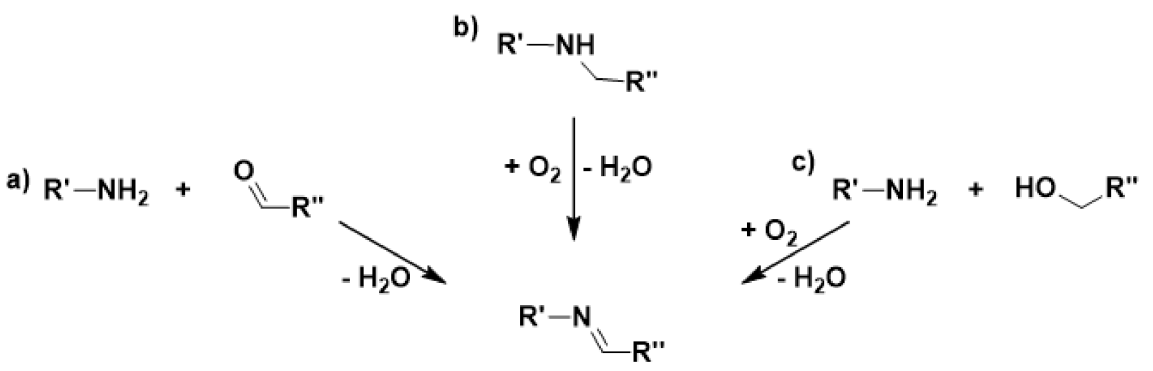

Scheme 4. Reaction pathways for imine synthesis from amines and carbonyl compounds.

Zhu et al., first described the applicability of gold in secondary $\mathrm{N}$-alkylbenzylamines oxidation to imine using $\mathrm{O}_{2}$ as only oxidant $\left(100{ }^{\circ} \mathrm{C}, 24 \mathrm{~h}, 1 \mathrm{~atm} \mathrm{O}_{2}\right)$ [144]. Following these pioneering studies, Baiker et al. [145-148] showed that AuNPs were supported onto 
a variety of inorganic oxides, namely, $\mathrm{Al}_{2} \mathrm{O}_{3}, \mathrm{TiO}_{2}, \mathrm{SiO}_{2}$, and $\mathrm{CeO}_{2}$, which are active catalysts in the aerobic oxidation of benzylamine to the corresponding imine; among the investigated catalysts, AuNPs- $\mathrm{CeO}_{2}$ catalyst outperformed all the others. Interestingly, the catalytic performances remarkably increased (conversion $=>99 \%$; selectivity $=84 \%$ in $1 \mathrm{~h})$ when the gold catalyst was in situ generated by treatment of a gold precursor $(\mathrm{AuCl}$; $\mathrm{AuCl}_{3} ; \mathrm{HAuCl}_{4} \cdot 3 \mathrm{H}_{2} \mathrm{O}$ ) with annealed ceria at $200{ }^{\circ} \mathrm{C}$, in the presence of the amine to be oxidized; in this case, the latter is supposed to be also the reductant leading to AuNPs with a large size distribution (20-300 nm). Under the same conditions, the oxidation of $\mathrm{N}$-tert-butylbenzylamine is complete in $55 \mathrm{~min}$, as well as that of indoline to indole [148]. This technique was further applied to the synthesis of a highly active and magnetically separable gold catalyst where the AuNPs are in situ generated and deposited onto ceria embedded with superparamagnetic Iron oxide [145]. Corma and Garcia showed that small AuNPs- $\mathrm{TiO}_{2}$ allows for the synthesis of dibenzylamine; an exponential increase of the catalytic activity was observed when the size of the AuNPs was decreased. The AuNPs-C catalyst is 30 times more active than the best $\mathrm{TiO}_{2}$-supported analogue, clearly demonstrating a strong support effect. The imine could be in situ hydrogenated in a one-pot two-step process to yield the corresponding secondary amine in high yields (98\%) [149].

Coming to the polymer supported AuNPs, Kobayashi et al., reported that the AuNPsclPS catalyst is active in dibenzylamine oxidation with amine conversion of $92-97 \%\left(140^{\circ} \mathrm{C}\right.$, $24 \mathrm{~h}$, xylene as solvent) [150]. Despite the high reaction temperature, the catalyst was successfully recycled at least three times, showing an increase of the catalytic activity in consecutive runs. The role of the Au loading and cluster size was thus investigated. AuNPs of 5-10 nm were found to be more active than those of $2-3 \mathrm{~nm}$. This result is quite unexpected when considering that the same catalyst showed an inverse trend in aerobic oxidation of alcohol. TEM analysis of the recycled AuNPs-clPS catalyst highlighted aggregation of the AuNPs during amine oxidation reaction. The increased activity of the recycled catalyst was thus attributed to the aggregation of the nanoparticles in the course of the reaction, in agreement with previous reports dealing with reorganization of the metal nanoparticle surface and size in the reaction with amines [150]. The relationship between the cluster size and reactivity could be due to a balance of a competitive absorption/desorption of the substrates and products where the adsorption strength of imines vs. amines might be larger on small clusters. Post functionalization of the polymer support with tertiary amine groups was found to further increase the catalyst activity at reaction temperature lower than $140{ }^{\circ} \mathrm{C}$. The authors proposed that the coordination of the tertiary amine group can promote de-coordination of the imine from the AuNPs surface leading to the observed catalytic activity. Oxidation of $N$-benzylaniline carrying EDGs and EWGs on the aromatic ring of the arylamine was also investigated to shed light on some features of the reaction mechanism. The oxidation rate is higher in the presence of EDGs, to support a carbocationic intermediate resulting from the hydride transfer from the benzylic position to gold that is the rate-determining step of the reaction. To test the generality of the reaction, a variety of $\mathrm{N}$-substrates was tested at $100{ }^{\circ} \mathrm{C}$. Indoline and tetrahydroquinoline were oxidized to indole and quinoline, respectively, whereas tetrahydroisoquinoline was oxidized to dihydroisoquinoline as a major product.

Various primary and secondary benzylamines could be successfully oxidized to the corresponding imines; aromatization reactions and one-pot deprotection of $p$-methoxybenzyl groups could be also achieved. Moreover, the catalyst could be reused several times by simple operations [150].

\subsubsection{Cross Coupling and Cascade of Oxidation Reactions}

Cascade reaction, also defined domino reaction, is a multistep reaction carried out using one pot in a single batch where each transformation is dependent on the previous one in the sense that the product of a reaction is the reagent of the following step. This methodology does not require isolation and purification of products or intermediates and protection of reactive functional group. AuNPs are very effective in cascade oxidation catalysis. 
Esters or amides are important targets in organic synthesis. They are typically obtained from carboxylic acids or activated carboxylic acid derivatives such as acid chlorides or acid anhydrides combined with alcohols or amines. In this context, direct oxidative ester formation from alcohols using molecular oxygen is an attractive and challenging goal for organic synthesis and green chemistry. Although oxidation of aldehydes to esters proceeds under mild conditions, examples from alcohols are rare. In particular, transformation of primary aliphatic alcohols to the corresponding esters is a difficult target.

A general methodology involving polymer protected MNPs was developed by Kobayashi et al. [126]. Oxidative esterification of $p$-methylbenzyl alcohol was successfully obtained with the AuNPs-(clPS\&CB) catalyst in wet methanol $\left(24 \mathrm{~h}, \mathrm{P}_{\mathrm{O} 2}=1 \mathrm{bar}\right.$, room temperature) using 0.5 equiv. of $\mathrm{K}_{2} \mathrm{CO}_{3}$ as base [151]. This esterification reaction is a three-step process: (i) oxidation of the alcohol to aldehyde, (ii) hydration of the aldehyde to hemiacetal, and (iii) a second oxidation in which the hemiacetal is converted into the methyl ester (see Scheme 5). Kinetic investigation of the reaction mechanism demonstrated that each step was of first order in the reagent and the second oxidation step was 30 times faster than the first step. Kobayashi et al., showed that the bimetallic (Au\&M)NPs-(clPS\&CB) catalysts ( $M=P d$, $\mathrm{Pt}$ ) better perform in the oxidative esterification of a variety of $\mathrm{n}$-alkyl, benzyl, and allyl alcohols at room temperature and atmospheric pressure of oxygen [126]. The oxidative esterification of 1-octanol is catalyzed by (Au\&Pd)NPs-(clPS\&CB) (Au: Pd ratio in the alloy $\sim 4: 1-3: 1)$ at $60{ }^{\circ} \mathrm{C}$ in methanol as solvent and $\mathrm{K}_{2} \mathrm{CO}_{3}$ as base, leading to the corresponding methyl ester in a quantitative conversion of the reagent in $24 \mathrm{~h}$ with selectivity of $76 \%$; the Au\&Pt analogue catalyst gave poor results. Under the same reaction conditions, a variety of primary and secondary alcohols were converted into the corresponding methyl esters with a selectivity of $78-97 \%$; the catalyst was reused up to 11 runs without observing deactivation. Interestingly, the (Au\&Pt)NPs-(clPS\&CB) catalyst preferentially produced oxidation of the alcohol to aldehyde or ketone. To explain these outcomes, the author proposed that the electronic transfer from $\mathrm{Pd}$ to $\mathrm{Au}$ produces acidic $\mathrm{Pd}$ atoms that favor hydration of the carbonyl intermediate to hemiacetal.

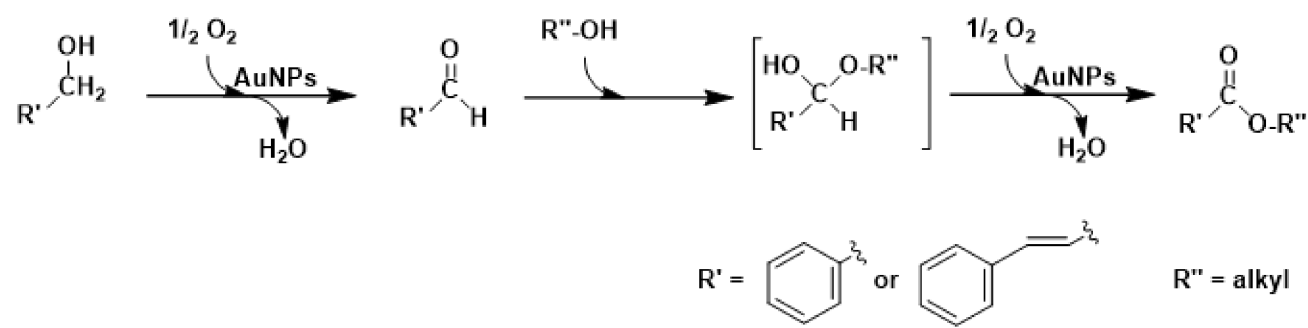

Scheme 5. Direct oxidative esterification of benzylic or allylic alcohols with alkyl alcohols promoted by AuNPs catalysts under mild reaction conditions.

An interesting target in this field is the oxidative esterification of alcohols from renewable resources such as cinnamyl alcohol or HMF [67,69]. The selective aerobic oxidation of cinnamyl alcohol to cinnamaldehyde, as well as direct oxidative esterification with primary and secondary aliphatic alcohols to produce the corresponding esters, were accomplished with the AuNPs-sPSB catalyst [67]. The rate constants were evaluated in the range of temperature $10-45^{\circ} \mathrm{C}$ for the two oxidation steps; the cinnamyl alcohol oxidation is faster than the oxidative esterification of cinnamaldehyde with methanol, ethanol, 2-propanol, 1-butanol, 1-hexanol, or 1-octanol (see Scheme 5). Interestingly, the first reaction step is of first order in the alcohol, whereas the second step involving the aliphatic alcohols is of zero order, while first-order kinetics was found with 1-phenyl ethanol. These results prompted the authors to propose that the polymer matrix allows for discrimination between the alcohols to be oxidized; the reactivity of the alkyl alcohols is controlled by diffusion through the amorphous part of the polymer support, while the aromatic alcohols readily migrate through the voids of the crystalline polymer phase. Following these results, oxidative esterification of HMF with methanol was attempted with AuNPs-sPSB (see Scheme 6) [69]. 
The choice of the solvent is fundamental in determining the polymer support phase and the corresponding activity/selectivity. DMA produced amorphization of the polymer phase, and the synthesis of 2,5-dimethylfurandicarboxilate (DMFC) was obtained in high yield at high temperature $\left(100-120^{\circ} \mathrm{C}\right)$. The nanoporous crystalline phase $\varepsilon$ was converted into the $\beta$ and $\gamma$ crystalline forms in DMF; these crystalline forms of the polymer support are not permeable and led to a decrease of both the catalytic activity and selectivity. Direct oxidation of HMF to FDCA in water is sluggish because of the poor swelling of the polymer matrix in this solvent. The addition of DMA and $\mathrm{KOH}$ allowed for the efficient oxidative esterification of HMF to DMFC, followed by base-catalyzed hydrolysis of the latter, leading to the straightforward synthesis of DFCA in good yields. Moreover, preliminary encouraging results were obtained in oxidation reactions carried out in DMF and DMA in the absence of an external base.

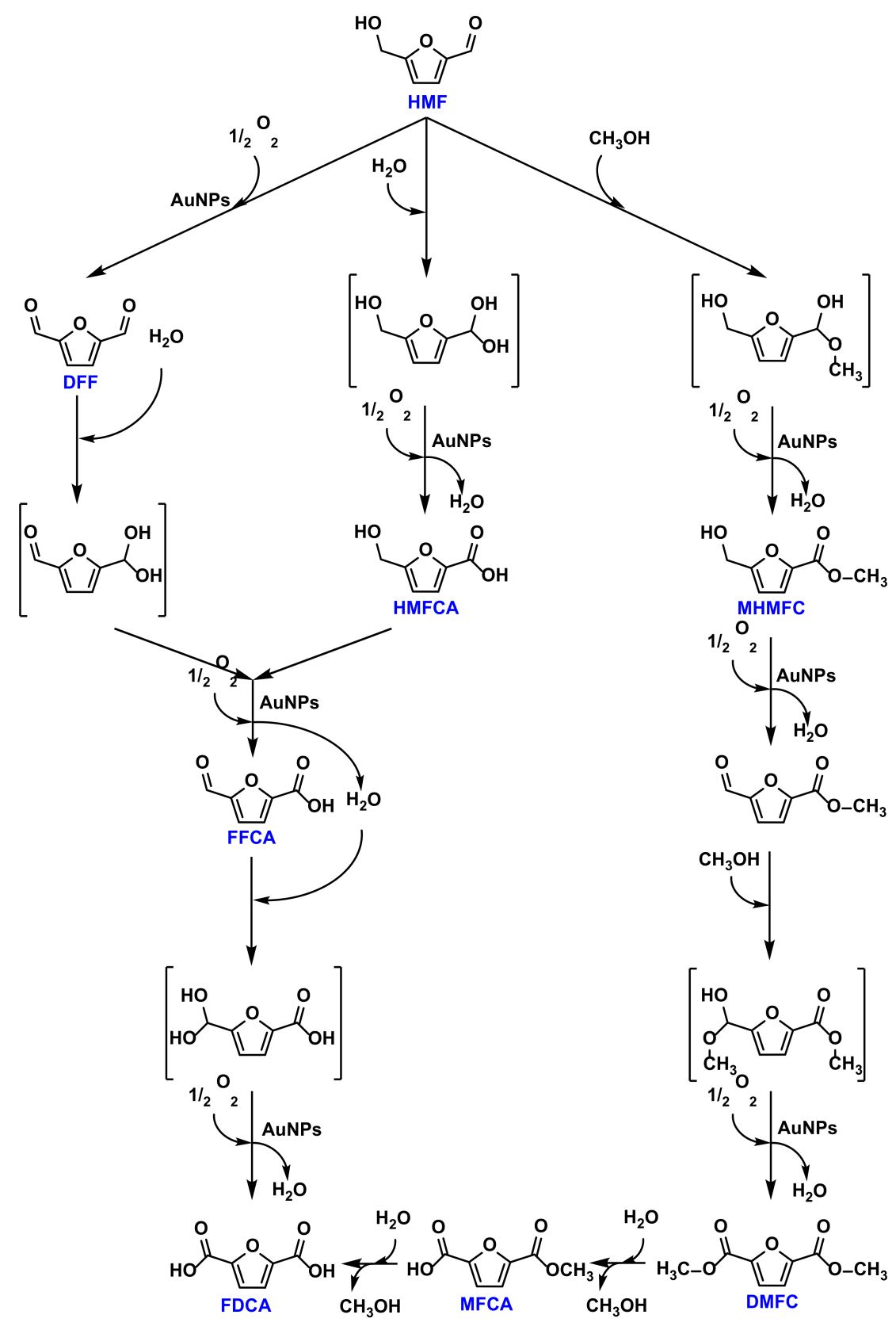

Scheme 6. HMF aerobic oxidation and oxidative esterification with methanol by polymer supported AuNPs. 
Amides and imines are important $\mathrm{N}$-containing intermediates for organic synthesis; actually, they play a major role in the pharmaceutical industry, biological systems, and material science, while imines are widely applied as electrophiles in many organic transformations such as cyclization, reduction, addition, and condensation. Traditional synthesis of amides and imines involves the reactions of carboxylic acids, or their derivatives such as acid chlorides and anhydrides, with amines. This approach suffers from toxicity issues and harsh reaction conditions. Recently, new methodologies towards the green synthesis of amides and imines have been developed, such as oxidative coupling of aldehydes and amines, hydrolysis of nitriles, and dehydrogenative coupling of alcohols and amines. Aerobic oxidative coupling of alcohols and amines offers the major advantages of mild reaction conditions, high efficiency, and a wide scope of substrates. This reaction is a tandem process composed of three consecutive steps: (i) oxidative dehydrogenation of alcohol to aldehyde, (ii) coupling of aldehyde and amine to form hemiaminal, and (iii) oxidation of hemiaminal to yield amide or dehydration to yield imine (Scheme 7).

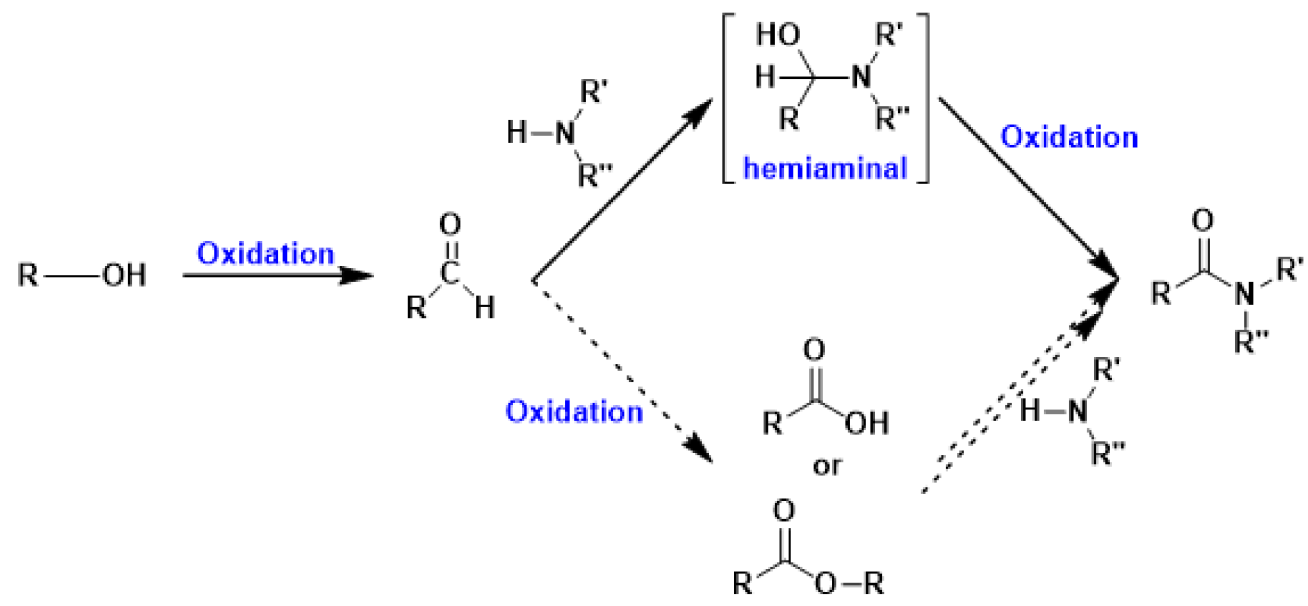

Scheme 7. Amide synthesis from alcohols and amines via tandem oxidative process.

Kobayashi et al., showed that AuNPs-clPS and AuNPs-(clPS\&CB) are very effective in the amide formation from alcohols and amine via a tandem oxidative process [152]. This oxidation process is very challenging, because of many possible side-reaction pathways and by-products, such as carboxylic acids and esters; in this cascade reaction, the key step is the oxidation of carbinolamine.

Aerobic amidation of the aliphatic alcohols, 3-phenylpropan-1-ol, and p-methylbenzyl alcohol was catalyzed by AuNPs-(clPS\&CB) using one equiv. of benzylamine, and one equiv. of $\mathrm{NaOH}$ in THF/water $(19: 1 v / v)$ yielded at $40{ }^{\circ} \mathrm{C}$ the corresponding benzylamide with an alcohol conversion of $83-85 \%$ and selectivity of $85 \%$; noteworthily, the Au\&Co catalyst produced the desired amides at $100 \%$ conversion and $96 \%$ of selectivity at $25{ }^{\circ} \mathrm{C}$ in $12 \mathrm{~h}$ [152]. The analogues bimetallic catalysts Au\&Fe and Au\&Ni yielded lower conversion and selectivity than Au\&Co catalyst under the same conditions. $p$-methylbenzaldehyde and benzylamine produced the corresponding imine as major product without observing further side reactions. When the reaction was carried out with $p$-methylbenzoic acid or $p$-methylbenzyl-4-methylbenzoate, no reaction was observed. These results suggest that benzoic acid and benzoate are not intermediate in this reaction that proceeds via carbinolamine intermediate. The Co atoms might stabilize the carbinolamine and inhibit the dehydration process; when the $\mathrm{Co}$ and $\mathrm{Au}$ atoms are in close proximity, the reaction proceeds with better selectivity. Actually, the scanning transmission electron microscopy (STEM) and energy dispersive spectroscopy (EDS) of the MNPs showed that Co does not exist inside the AuNPs but is dispersed throughout the polymer/CB composite; thus, the AuNPs and CoNPs lie in close proximity without producing a real alloy. The catalyst was recovered by simple filtration and reused without significant loss of activity. To demonstrate the general applicability of (Au\&Co)-(clPS\&CB), a variety of alcohols and 
alkylamines were tested in amidation reactions showing from good to excellent yields. However, the data shown in this work do not clearly explain the remarkable effects of the bimetallic Au\&Co catalyst for the selective formation of amide and the difference in activities of AuNPs-(clPS\&CB) and (Au\&Co)-(clPS\&CB).

On the basis of these outcomes, the same authors developed the (Au\&Pd)-(clPS\&CB) catalyst for the synthesis of imines from alcohols and amine [153]. They found that (Au\&Co)-(clPS\&CB) (1 equiv. of $\mathrm{NaOH}$, at $\left.25^{\circ} \mathrm{C}\right)$ in THF-trifluoroethanol (TFE) (9:1 v/v) minimizes the dehydration step and leads to the selective formation of the imine in high yield and selectivity; the amount of $\mathrm{NaOH}$ could be also successfully reduced to 0.25 equiv. to make the process more sustainable. Under the optimized conditions, a variety of imines could be obtained under analytically pure form $(>95 \%)$ after simple filtration of the catalyst, simple extraction of the organic phase from water solution, and drying in vacuo to remove inorganics and organic volatiles. The catalyst could be reused at least five times without noticeable loss of catalytic activity. A pre-treatment of the (Au\&Pd)-(clPS\&CB) catalyst was required for the recycling, similar to what was observed in amidation reactions. The pre-treatment consists of washing with water and THF, followed by heating at $170{ }^{\circ} \mathrm{C}$ for $4 \mathrm{~h}$; noteworthily, this process does not affect the catalyst morphology.

(Au\&Pd)NPs supported onto a commercial ionic-exchange resin were found to be active in the aerobic oxidative coupling of alcohols with amines [154]. Interestingly, the authors were able to address the selectivity of the reaction toward imine or amide at variance of the nanoparticle composition. Au-rich alloy $\left(\mathrm{Au}_{6} \mathrm{Pd}\right)$ preferentially absorbs aldehydes resulting from the alcohol oxidation, which in turn yields the corresponding amides in the presence of amines. Pd-rich alloys (e.g., $\mathrm{AuPd}_{4}$ ) readily desorb the aldehyde, which then undergoes condensation with amines to produce imines.

AuNPs were also supported onto Amberlite-400 and Amberlite-120 (polystyrene resins functionalized with ammonium and sulfonate groups, respectively) and tested in the coupling of epoxides with $\mathrm{CO}_{2}$. While the former is extremely efficient in activating both epoxides and $\mathrm{CO}_{2}$, the latter is poorly active as a result of the presence of sulfonate moieties [155]. This polymer-immobilized nanogold could also be an effective catalyst for carbonylation of amines with $\mathrm{CO}_{2}$ to yield the corresponding disubstituted ureas. The reaction of cyclohexylamine and benzyl amine with $\mathrm{CO}_{2}$ smoothly yields disubstituted ureas (carbamates); the yields are excellent, and the process is highly efficient, showing a turnover frequency of $3000 \mathrm{~mol} / \mathrm{mol}_{\text {cat }} \mathrm{h}$. Following this report, Sun and co-workers reported the direct synthesis of styrene carbonate from styrene and $\mathrm{CO}_{2}$ catalyzed by AuNPs supported on R201 resin (a quaternary cationic ammonium polymer) [156]. Anhydrous tert-butyl hydroperoxide (TBHP) was used to oxidize in situ styrene to styrene oxide that in turn couples with $\mathrm{CO}_{2}$ to form the cyclic carbonate. The reaction was carried out in two steps using Au loading of $0.1-0.005 \%$. The oxidation reaction was carried out at $80{ }^{\circ} \mathrm{C}$ for $3 \mathrm{~h}$, whereas the cycloaddition with $\mathrm{CO}_{2}$ was conducted for $4 \mathrm{~h}$ at $100{ }^{\circ} \mathrm{C}$; the conversion of styrene in the first step is of $89-91 \%$, and the selectivity in styrene carbonate of $97-100 \%$. A cooperative role of AuNPs and the quaternary ammonium functionalities was proposed to play a vital role on both reactions.

AuNPs-PVP (5-10\% Au) efficiently catalyzes oxidative $N$-formylation of $N$-phenyl and $\mathrm{N}$-alkyl amines with different structures in methanol with $\mathrm{LiOH}$ as base additive [156]. The reaction pathway preliminary involves methanol oxidation to formaldehyde followed by the nucleophilic attack of the amine to the carbonyl group, leading to the formation of the hemiaminal intermediate that undergoes further oxidation to formamide; the formylation of $N$-methylaniline was successfully realized with good yields (81-94\%).

The scope of the reaction was thus extended to a family of substituted anilines, cyclic arylamine, and piperidine using $\mathrm{NaOH}$ as base $(100 \mathrm{~mol} \%)$ and formaline $(150 \mathrm{~mol} \%)$ as co-reagent; the corresponding $\mathrm{N}$-formylated products were obtained with a selectively of $81-99 \%$ (anilines), $81-98 \%$ (cyclic amine), and $88 \%$ (piperidine), respectively [157]. Noteworthily, the formation of the hemiaminal intermediate was suggested as the key reaction step. In another report, the same research group showed that the AuNPs-PVP 
catalyst promotes the selective aerobic oxidation of cyclic secondary amines at the $\alpha$ position of the $\mathrm{N}$ atom under more drastic conditions (methanol/water 1:2 $v / v$ at reflux; $200 \mathrm{~mol} \%$ of $\mathrm{LiOH}$ ) to produce lactams [158]. Oxidation of 1,2,3,4-tetrahydroquinoline in water to produce 3,4-dihydroquinolin-2-one was obtained at $90{ }^{\circ} \mathrm{C}$ in $24 \mathrm{~h}$ with $99 \%$ of isolated yield. This outcome suggests that the cyclic amine oxidation to cyclic imine proceeds faster, under the conditions explored, than methanol oxidation; further oxidation of the hemiaminal intermediate produces the corresponding lactam.

\section{Concluding Remarks and Outlook}

Polymer supported AuNPs have gained a relevant position in the field of catalysis for sustainable organic synthesis. Nanostructured gold catalysts present excellent properties in terms of selectivity and activities in both oxidation and reduction reactions; cascades of organic reactions and novel reaction pathways have been also discovered during the last two decades to yield chemicals of interest for industry. Researchers active in the field have often questioned the real advantage of using organic polymer supports instead of the most conventional inorganic supports. Organic polymers are indeed less thermally stable than metal oxides, and gold requires harsh reaction condition. Covalent crosslinking of the polymer matrix is thus often necessary to prevent metal leaching or coalescence of the nanoparticles because of the weak interaction between the nanoparticles and the support. Despite this, organic polymer supports exhibit peculiar properties and specific advantages in catalysis. In the catalyst synthesis, functional polymers can act as both protecting and reducing agents to simplify the procedure; at the same time, the catalyst can be recovered from the reaction media by smart stimuli, as variation of $\mathrm{pH}$, of temperature or addition of non-solvents. The tuning the hydrophilic or hydrophobic properties of the support and the resulting polymer swelling in the reaction solvent, or even in neat reactants, yielded a fast and selective diffusion of the substrates to the catalytic sites located inside the support to produce unprecedented selectivity, as demonstrated in, e.g., selective oxidation of the alcohols and their oxidative esterification. Microporous and mesoporous polymers, with pore sizes in the range of 2-50nm or even lower, have been also applied to this purpose and design micro-reactor environments with proper selectivity. Vesicles and micelles consisting of amphiphilic polymers have been used for, e.g., the efficient reduction of nitroarenes in water.

Sustainability requires mild operative reaction conditions and a limited use of cocatalysts; in this respect, the polymer-entrapped gold catalysts work at a low temperature but need a significant amount of Brønsted base in, e.g., alcohol oxidation or acidic promoters in the direct synthesis of hydrogen peroxide or hydroamination. Post-functionalization of the polymer support with the anchoring of Brønsted acidic or basic functionalities can lead to $\mathrm{pH}$ modulation of the reaction environment and recyclable catalysts; this field is still only partially explored but it is of great potential.

The effects of polymer crystallinity, micro-and nano-scale morphology, and permeability of the polymer support to organic reagents have been only partially explored and deserve further investigation. Crystalline domains in the polymer matrix act as physical and reversible points of reticulation, conferring to the catalyst improved resistance to leaching and sintering of gold.

From a mechanistic point of view, AuNPs entrapped in hydrocarbon polymers lead to naked nanoparticles whose catalytic properties can be compared with those of AuNPs deposited on metal oxides when the latter can co-operate in a synergistic way in catalysis; this can help to shed light on the effective cooperative effect of the support and the metal catalyst.

The gold rush in catalysis is thus not over, and novel breakthroughs are expected in this field for the design of more sustainable chemical processes.

Author Contributions: Conceptualization, A.G.; data curation, A.G. and A.B.; writing-original draft preparation, A.G. and A.B.; writing-review and editing, A.G. and A.B. Both authors have read and agreed to the published version of the manuscript. 
Funding: The authors acknowledge for funding the "Ministero dell'Istruzione, dell'Università e della Ricerca MIUR" (PRIN2017 Grant), the “Università degli Studi di Salerno" (FARB Grants), and the "Centro Universitario per la Previsione e Prevenzione Grandi Rischi C.U.G.R.I.".

Conflicts of Interest: The authors declare no conflict of interest.

\section{References}

1. Pandey, S.; Nanda, K.K. Au nanocomposite based chemiresistive ammonia sensor for health monitoring. ACS Sens. 2016, 1, 55-62. [CrossRef]

2. Pandey, S.; Goswami, G.K.; Nanda, K.K. Nanocomposite based flexible ultrasensitive resistive gas sensor for chemical reactions studies. Sci. Rep. 2013, 3, 2082. [CrossRef]

3. Pandey, S.; Ramontja, J. Sodium alginate stabilized silver nanoparticles-silica nanohybrid and their antibacterial characteristics. Int. J. Biol. Macromol. 2016, 93, 712-723. [CrossRef]

4. Pandey, S.; Mishra, S.B. Catalytic reduction of p-nitrophenol by using platinum nanoparticles stabilised by guar gum. Carbohydr. Polym. 2014, 113, 525-531. [CrossRef]

5. Capek, I. Noble Metal Nanoparticles; Springer: Berlin/Heidelberg, Germany, 2017.

6. Hutchings, G.J. Heterogeneous gold catalysis. ACS Cent. Sci. 2018, 4, 1095-1101. [CrossRef]

7. Rönsch, S.; Schneider, J.; Matthischke, S.; Schlüter, M.; Götz, M.; Lefebvre, J.; Prabhakaran, P.; Bajohr, S. Review on methanationFrom fundamentals to current projects. Fuel 2016, 166, 276-296. [CrossRef]

8. Curry, S.W. Platinum catalysts in petroleum refining. Platin. Met. Rev. 1957, 1, 38-43.

9. Haruta, M.; Kobayashi, T.; Sano, H.; Yamada, N. Novel gold catalysts for the oxidation of carbon monoxide at a temperature far below $0{ }^{\circ} \mathrm{C}$. Chem. Lett. 1987, 16, 405-408. [CrossRef]

10. Claus, P.; Brückner, A.; Mohr, C.; Hofmeister, H. Supported gold nanoparticles from quantum dot to mesoscopic size scale: Effect of electronic and structural properties on catalytic hydrogenation of conjugated functional groups. J. Am. Chem. Soc. 2000, 122, 11430-11439. [CrossRef]

11. Priecel, P.; Salami, H.A.; Padilla, R.H.; Zhong, Z.; Lopez-Sanchez, J.A. Anisotropic gold nanoparticles: Preparation and applications in catalysis. Chin. J. Catal. 2016, 37, 1619-1650. [CrossRef]

12. Sharma, G.; Kumar, A.; Sharma, S.; Naushad, M.; Dwivedi, R.P.; Alothman, Z.A.; Mola, G.T. Novel development of nanoparticles to bimetallic nanoparticles and their composites: A review. J. King Saud Univ. Sci. 2019, 31, 257-269. [CrossRef]

13. Sun, Q.; Dai, Z.; Meng, X.; Xiao, F.-S. Porous polymer catalysts with hierarchical structures. Chem. Soc. Rev. 2015, 44, 6018-6034. [CrossRef]

14. Zhang, Y.; Riduan, S.N. Functional porous organic polymers for heterogeneous catalysis. Chem. Soc. Rev. 2012, 41, 2083-2094. [CrossRef]

15. Stratakis, M.; Garcia, H. Catalysis by supported gold nanoparticles: Beyond aerobic oxidative processes. Chem. Rev. 2012, 112, 4469-4506. [CrossRef]

16. Zhang, Y.; Cui, X.; Shi, F.; Deng, Y. Nano-gold catalysis in fine chemical synthesis. Chem. Rev. 2012, 112, 2467-2505. [CrossRef]

17. Ishida, T.; Haruta, M. Gold catalysts: Towards sustainable chemistry. Angew. Chem. Int. Ed. 2007, 46, 7154-7156. [CrossRef]

18. Bond, G.; Louis, C.; Thompson, D.T. Catalysis by Gold; Imperial College Press: London, UK, 2006. [CrossRef]

19. Prati, L.; Villa, A. Gold Catalysis: Preparation, Characterization, and Applications; Jenny Stanford Publishing: Singapore, 2015. [CrossRef]

20. Dzhardimalieva, G.I.; Uflyand, I.E. Preparation of metal-polymer nanocomposites by chemical reduction of metal ions: Functions of polymer matrices. J. Polym. Res. 2018, 25, 255. [CrossRef]

21. Tsubota, S.; Haruta, M.; Kobayashi, T.; Ueda, A.; Nakahara, Y.; Poncelet, G. Preparation of Catalysts V; Poncelet, G., Jacobs, J.A., Delmon, B., Eds.; Elsevier: Amsterdam, The Netherlands, 1991; pp. 695-704.

22. Haruta, M.; Tsubota, S.; Kobayashi, T.; Kageyama, H.; Genet, M.J.; Delmon, B. Low-temperature oxidation of CO over gold supported on $\mathrm{TiO}_{2}, \alpha-\mathrm{Fe}_{2} \mathrm{O}_{3}$, and $\mathrm{Co}_{3} \mathrm{O}_{4}$. J. Catal. 1993, 144, 175-192. [CrossRef]

23. Dzhardimalieva, G.I.; Zharmagambetova, A.K.; Kudaibergenov, S.E.; Uflyand, I.E. Polymer-immobilized clusters and metal nanoparticles in catalysis. Kinet. Catal. 2020, 61, 198-223. [CrossRef]

24. Pomogailo, A.D.; Dzhardimalieva, G.I. Nanostructured Materials Preparation via Condensation Ways; Springer: Berlin/Heidelberg, Germany, 2014. [CrossRef]

25. Vreeland, E.C.; Watt, J.; Schober, G.B.; Hance, B.G.; Austin, M.J.; Price, A.D.; Fellows, B.D.; Monson, T.C.; Hudak, N.S.; MaldonadoCamargo, L.; et al. Enhanced nanoparticle size control by extending Lamer's mechanism. Chem. Mater. 2015, 27, 6059-6066. [CrossRef]

26. LaMer, V.K.; Dinegar, R.H. Theory, production and mechanism of formation of monodispersed hydrosols. J. Am. Chem. Soc. 1950, 72, 4847-4854. [CrossRef]

27. Parveen, R.; Tremiliosi-Filho, G. A step ahead towards the green synthesis of monodisperse gold nanoparticles: The use of crude glycerol as a greener and low-cost reducing agent. RSC Adv. 2016, 6, 95210-95219. [CrossRef]

28. Kumar, A.; Bhatt, M.; Vyas, G.; Bhatt, S.; Paul, P. Sunlight induced preparation of functionalized gold nanoparticles as recyclable colorimetric dual sensor for aluminum and fluoride in water. ACS Appl. Mater. Interfaces 2017, 9, 17359-17368. [CrossRef] 
29. Das, S.; Pandey, A.; Pal, S.; Kolya, H.; Tripathy, T. Green synthesis, characterization and antibacterial activity of gold nanoparticles using hydroxyethyl starch-g-poly (methylacrylate-co-sodium acrylate): A novel biodegradable graft copolymer. J. Mol. Liq. 2015, 212, 259-265. [CrossRef]

30. Otari, S.V.; Patel, S.K.S.; Jeong, J.-H.; Lee, J.H.; Lee, J.-K. A green chemistry approach for synthesizing thermostable antimicrobial peptide-coated gold nanoparticles immobilized in an alginate biohydrogel. RSC Adv. 2016, 6, 86808-86816. [CrossRef]

31. Valdez, J.; Gómez, I. One-step green synthesis of metallic nanoparticles using sodium alginate. J. Nanomater. 2016, $2016,9790345$. [CrossRef]

32. Chairam, S.; Konkamdee, W.; Parakhun, R. Starch-supported gold nanoparticles and their use in 4-nitrophenol reduction. J. Saudi Chem. Soc. 2017, 21, 656-663. [CrossRef]

33. Abrica-González, P.; Zamora-Justo, J.A.; Sotelo-López, A.; Vázquez-Martínez, G.R.; Balderas-López, J.A.; Muñoz-Diosdado, A.; Ibáñez-Hernández, M. Gold nanoparticles with chitosan, N-acylated chitosan, and chitosan oligosaccharide as DNA carriers. Nanoscale Res. Lett. 2019, 14, 258. [CrossRef] [PubMed]

34. Manivasagan, P.; Bharathiraja, S.; Bui, N.Q.; Lim, I.G.; Oh, J. Paclitaxel-loaded chitosan oligosaccharide-stabilized gold nanoparticles as novel agents for drug delivery and photoacoustic imaging of cancer cells. Int. J. Pharm. 2016, 511, 367-379. [CrossRef] [PubMed]

35. Chen, X.; Zhao, D.; An, Y.; Zhang, Y.; Cheng, J.; Wang, B.; Shi, L. Formation and catalytic activity of spherical composites with surfaces coated with gold nanoparticles. J. Colloid Interface Sci. 2008, 322, 414-420. [CrossRef]

36. Miyamura, H.; Matsubara, R.; Miyazaki, Y.; Kobayashi, S. Aerobic oxidation of alcohols at room temperature and atmospheric conditions catalyzed by reusable gold nanoclusters stabilized by the benzene rings of polystyrene derivatives. Angew. Chem. Int. Ed. 2007, 46, 4151-4154. [CrossRef]

37. Buonerba, A.; Cuomo, C.; Sánchez, S.O.; Canton, P.; Grassi, A. Gold nanoparticles incarcerated in nanoporous syndiotactic polystyrene matrices as new and efficient catalysts for alcohol oxidations. Chem. Eur. J. 2012, 18, 709-715. [CrossRef]

38. Sakai, T.; Alexandridis, P. Single-step synthesis and stabilization of metal nanoparticles in aqueous pluronic block copolymer solutions at ambient temperature. Langmuir 2004, 20, 8426-8430. [CrossRef]

39. Sakai, T.; Alexandridis, P. Mechanism of gold metal ion reduction, nanoparticle growth and size control in aqueous amphiphilic block copolymer solutions at ambient conditions. J. Phys. Chem. B 2005, 109, 7766-7777. [CrossRef]

40. Goy-López, S.; Castro, E.; Taboada, P.; Mosquera, V. Block copolymer-mediated synthesis of size-tunable gold nanospheres and nanoplates. Langmuir 2008, 24, 13186-13196. [CrossRef]

41. Saldías, C.; Leiva, A.; Quezada, C.; Jaque, P.; Gargallo, L.; Radic, D. Structural effects of amphiphilic block copolymers on the gold nanoplates synthesis. Experimental and theoretical study. Eur. Polym. J. 2011, 47, 1866-1876. [CrossRef]

42. Dai, Y.; Li, Y.; Wang, S. ABC triblock copolymer-stabilized gold nanoparticles for catalytic reduction of 4-nitrophenol. J. Catal. 2015, 329, 425-430. [CrossRef]

43. Alkilany, A.M.; Yaseen, A.I.B.; Kailani, M.H. Synthesis of monodispersed gold nanoparticles with exceptional colloidal stability with grafted polyethylene glycol-g-polyvinyl alcohol. J. Nanomater. 2015, 2015, 712359. [CrossRef]

44. Ruiz-Muelle, A.B.; Kuttner, C.; Alarcón-Fernández, C.; López-Romero, J.M.; Uhlmann, P.; Contreras-Cáceres, R.; Fernández, I. Hybrid surfaces active in catalysis based on gold nanoparticles modified with redox-active pendants and polymer brushes. Appl. Surf. Sci. 2019, 496, 143598. [CrossRef]

45. Höller, R.P.M.; Kuttner, C.; Mayer, M.; Wang, R.; Dulle, M.; Contreras-Cáceres, R.; Fery, A.; Liz-Marzán, L.M. Colloidal superstructures with triangular cores: Size effects on SERS efficiency. ACS Photonics 2020, 7, 1839-1848. [CrossRef]

46. Tebbe, M.; Kuttner, C.; Männel, M.; Fery, A.; Chanana, M. Colloidally stable and surfactant-free protein-coated gold nanorods in biological media. ACS Appl. Mater. Interfaces 2015, 7, 5984-5991. [CrossRef]

47. De Barros, H.R.; García, I.; Kuttner, C.; Zeballos, N.; Camargo, P.H.C.; de Torresi, S.I.C.; López-Gallego, F.; Liz-Marzán, L.M. Mechanistic insights into the light-driven catalysis of an immobilized lipase on plasmonic nanomaterials. ACS Catal. 2021, 11, 414-423. [CrossRef]

48. Faraday, M.X. The bakerian lecture. Experimental relations of gold (and other metals) to light. Philos. Trans. R. Soc. Lond. 1857, 147, 145-181. [CrossRef]

49. Turkevich, J.; Stevenson, P.C.; Hillier, J. A study of the nucleation and growth processes in the synthesis of colloidal gold. Discuss. Faraday Soc. 1951, 11, 55-75. [CrossRef]

50. Frens, G. Controlled nucleation for the regulation of the particle size in monodisperse gold suspensions. Nat. Phys. Sci. 1973, 241, 20-22. [CrossRef]

51. Sundaram, D.; Yang, V.; Yetter, R.A. Metal-based nanoenergetic materials: Synthesis, properties, and applications. Prog. Energy Combust. Sci. 2017, 61, 293-365. [CrossRef]

52. Kinayyigit, S.; Philippot, K. Chapter 4-Organometallic approach for the synthesis of noble metal nanoparticles: Towards application in colloidal and supported nanocatalysis. In Metal Nanoparticles for Catalysis: Advances and Applications; The Royal Society of Chemistry: London, UK, 2014; pp. 47-82. [CrossRef]

53. Bronstein, L.M.; Matveeva, V.G.; Sulman, E.M. Nanoparticulate catalysts based on nanostructured polymers. In Nanoparticles and Catalysis; Astruc, D., Ed.; Wiley-VCH: Weinheim, Germany, 2007; pp. 93-127. [CrossRef]

54. Ma, Z.; Tao, F. Chapter 8-Metal salt-based gold nanocatalysts. In Metal Nanoparticles for Catalysis: Advances and Applications; The Royal Society of Chemistry: London, UK, 2014; pp. 157-171. [CrossRef] 
55. Caseri, W.R. In situ synthesis of polymer-embedded nanostructures. In Nanocomposites; Nicolais, L., Carotenuto, G., Eds.; Wiley-VCH: Weinheim, Germany, 2013; pp. 45-72. [CrossRef]

56. Grisel, R.; Weststrate, K.-J.; Gluhoi, A.; Nieuwenhuys, B.E. Catalysis by gold nanoparticles. Gold Bull. 2002, 35, 39-45. [CrossRef]

57. Liu, X.Y.; Wang, A.; Zhang, T.; Mou, C.-Y. Catalysis by gold: New insights into the support effect. Nano Today 2013, 8, $403-416$. [CrossRef]

58. Astruc, D. Transition-metal nanoparticles in catalysis: From historical background to the state-of-the art. In Nanoparticles and Catalysis; Astruc, D., Ed.; Wiley-VCH: Weinheim, Germany, 2007; pp. 1-48. [CrossRef]

59. Akiyama, R.; Kobayashi, S. "Microencapsulated" and related catalysts for organic chemistry and organic synthesis. Chem. Rev. 2009, 109, 594-642. [CrossRef]

60. Miyamura, H.; Kobayashi, S. Tandem oxidative processes catalyzed by polymer-incarcerated multimetallic nanoclusters with molecular oxygen. Acc. Chem. Res. 2014, 47, 1054-1066. [CrossRef]

61. Shan, J.; Tenhu, H. Recent advances in polymer protected gold nanoparticles: Synthesis, properties and applications. Chem. Commun. 2007, 44, 4580-4598. [CrossRef] [PubMed]

62. Shi, F.; Deng, Y. Polymer-immobilized gold catalysts for the efficient and clean syntheses of carbamates and symmetric ureas by oxidative carbonylation of aniline and its derivatives. J. Catal. 2002, 211, 548-551. [CrossRef]

63. Burato, C.; Centomo, P.; Pace, G.; Favaro, M.; Prati, L.; Corain, B. Generation of size-controlled palladium(0) and gold(0) nanoclusters inside the nanoporous domains of gel-type functional resins: Part II: Prospects for oxidation catalysis in the liquid phase. J. Mol. Catal. A 2005, 238, 26-34. [CrossRef]

64. Tsunoyama, H.; Sakurai, H.; Ichikuni, N.; Negishi, Y.; Tsukuda, T. Colloidal gold nanoparticles as catalyst for carbon-carbon bond formation: Application to aerobic homocoupling of phenylboronic acid in water. Langmuir 2004, 20, 11293-11296. [CrossRef] [PubMed]

65. Pastoriza-Santos, I.; Liz-Marzán, L.M. Formation of PVP-protected metal nanoparticles in DMF. Langmuir 2002, 18, 2888-2894. [CrossRef]

66. Litta, A.D.; Buonerba, A.; Casu, A.; Falqui, A.; Capacchione, C.; Franconetti, A.; Garcia, H.; Grassi, A. Highly Efficient Hydroamination of Phenylacetylenes with Anilines Catalysed by Gold Nanoparticles Embedded in Nanoporous Polymer Matrix: Insight into the Reaction Mechanism by Kinetic and DFT Investigations. J. Catal. 2021, in press. [CrossRef]

67. Buonerba, A.; Noschese, A.; Grassi, A. Highly efficient direct aerobic oxidative esterification of cinnamyl alcohol with alkyl alcohols catalysed by gold nanoparticles incarcerated in a nanoporous polymer matrix: A tool for investigating the role of the polymer host. Chem. Eur. J. 2014, 20, 5478-5486. [CrossRef]

68. Noschese, A.; Buonerba, A.; Canton, P.; Milione, S.; Capacchione, C.; Grassi, A. Highly efficient and selective reduction of nitroarenes into anilines catalyzed by gold nanoparticles incarcerated in a nanoporous polymer matrix: Role of the polymeric support and insight into the reaction mechanism. J. Catal. 2016, 340, 30-40. [CrossRef]

69. Buonerba, A.; Impemba, S.; Litta, A.D.; Capacchione, C.; Milione, S.; Grassi, A. Aerobic oxidation and oxidative esterification of 5-hydroxymethylfurfural by gold nanoparticles supported on nanoporous polymer host matrix. ChemSusChem 2018, 11, 3139-3149. [CrossRef]

70. Mitsudome, T.; Kaneda, K. Gold nanoparticle catalysts for selective hydrogenations. Green Chem. 2013, 15, 2636-2654. [CrossRef]

71. Bond, G.C.; Sermon, P.A.; Webb, G.; Buchanan, D.A.; Wells, P.B. Hydrogenation over supported gold catalysts. J. Chem. Soc. Chem. Commun. 1973, 13, 444b-445. [CrossRef]

72. Okumura, M.; Akita, T.; Haruta, M. Hydrogenation of 1,3-butadiene and of crotonaldehyde over highly dispersed Au catalysts. Catal. Today 2002, 74, 265-269. [CrossRef]

73. Zhang, X.; Shi, H.; Xu, B.-Q. Vital roles of hydroxyl groups and gold oxidation states in $\mathrm{Au} / \mathrm{ZrO}_{2}$ catalysts for 1,3-butadiene hydrogenation. J. Catal. 2011, 279, 75-87. [CrossRef]

74. Yang, X.-F.; Wang, A.-Q.; Wang, Y.-L.; Zhang, T.; Li, J. Unusual selectivity of gold catalysts for hydrogenation of 1,3-butadiene toward cis-2-butene: A joint experimental and theoretical investigation. J. Phys. Chem. C 2010, 114, 3131-3139. [CrossRef]

75. Seregina, M.V.; Bronstein, L.M.; Platonova, O.A.; Chernyshov, D.M.; Valetsky, P.M.; Hartmann, J.; Wenz, E.; Antonietti, M. Preparation of noble-metal colloids in block copolymer micelles and their catalytic properties in hydrogenation. Chem. Mater. 1997, 9, 923-931. [CrossRef]

76. Bronstein, L.M.; Chernyshov, D.M.; Volkov, I.O.; Ezernitskaya, M.G.; Valetsky, P.M.; Matveeva, V.G.; Sulman, E.M. Structure and properties of bimetallic colloids formed in polystyrene-block-poly-4-vinylpyridine micelles: Catalytic behavior in selective hydrogenation of dehydrolinalool. J. Catal. 2000, 196, 302-314. [CrossRef]

77. Mertens, P.G.N.; Poelman, H.; Ye, X.; Vankelecom, I.F.J.; Jacobs, P.A.; de Vos, D.E. Au0 nanocolloids as recyclable quasihomogeneous metal catalysts in the chemoselective hydrogenation of $\alpha, \beta$-unsaturated aldehydes and ketones to allylic alcohols. Catal. Today 2007, 122, 352-360. [CrossRef]

78. Biondi, I.; Laurenczy, G.; Dyson, P.J. Synthesis of gold nanoparticle catalysts based on a new water-soluble ionic polymer. Inorg. Chem. 2011, 50, 8038-8045. [CrossRef] [PubMed]

79. Hu, T.; Zhang, L.; Wang, Y.; Yue, Z.; Li, Y.; Ma, J.; Xiao, H.; Chen, W.; Zhao, M.; Zheng, Z.; et al. Defect engineering in $\mathrm{Pd} / \mathrm{NiCO}_{2} \mathrm{O}_{4-\mathrm{x}}$ for selective hydrogenation of $\alpha, \beta$-unsaturated carbonyl compounds under ambient conditions. ACS Sustain. Chem. Eng. 2020, 8, 7851-7859. [CrossRef] 
80. Mohr, C.; Hofmeister, H.; Claus, P. The influence of real structure of gold catalysts in the partial hydrogenation of acrolein. J. Catal. 2003, 213, 86-94. [CrossRef]

81. Wang, M.-M.; He, L.; Liu, Y.-M.; Cao, Y.; He, H.-Y.; Fan, K.-N. Gold supported on mesostructured ceria as an efficient catalyst for the chemoselective hydrogenation of carbonyl compounds in neat water. Green Chem. 2011, 13, 602-607. [CrossRef]

82. Takale, B.S.; Wang, S.; Zhang, X.; Feng, X.; Yu, X.; Jin, T.; Bao, M.; Yamamoto, Y. Chemoselective reduction of $\alpha, \beta$-unsaturated aldehydes using an unsupported nanoporous gold catalyst. Chem. Commun. 2014, 50, 14401-14404. [CrossRef]

83. Ju, K.-S.; Parales, R.E. Nitroaromatic compounds, from synthesis to biodegradation. Microbiol. Mol. Biol. Rev. 2010, 74, 250-272. [CrossRef]

84. Seo, E.; Kim, J.; Hong, Y.; Kim, Y.S.; Lee, D.; Kim, B.-S. Double hydrophilic block copolymer templated Au nanoparticles with enhanced catalytic activity toward nitroarene reduction. J. Phys. Chem. C 2013, 117, 11686-11693. [CrossRef]

85. Zhao, P.; Li, N.; Salmon, L.; Liu, N.; Ruiz, J.; Astruc, D. How a simple “clicked" PEGylated 1,2,3-triazole ligand stabilizes gold nanoparticles for multiple usage. Chem. Commun. 2013, 49, 3218-3220. [CrossRef]

86. Xiao, C.; Chen, S.; Zhang, L.; Zhou, S.; Wu, W. One-pot synthesis of responsive catalytic Au@PVP hybrid nanogels. Chem. Commun. 2012, 48, 11751-11753. [CrossRef]

87. Esumi, K.; Hayakawa, K.; Yoshimura, T. Morphological change of gold-dendrimer nanocomposites by laser irradiation. J. Colloid Interface Sci. 2003, 268, 501-506. [CrossRef]

88. Hayakawa, K.; Yoshimura, T.; Esumi, K. Preparation of gold-dendrimer nanocomposites by laser irradiation and their catalytic reduction of 4-nitrophenol. Langmuir 2003, 19, 5517-5521. [CrossRef]

89. Li, M.; Chen, G. Revisiting catalytic model reaction p-nitrophenol/NaBH4 using metallic nanoparticles coated on polymeric spheres. Nanoscale 2013, 5, 11919-11927. [CrossRef]

90. Han, J.; Li, L.; Guo, R. Novel approach to controllable synthesis of gold nanoparticles supported on polyaniline nanofibers. Macromolecules 2010, 43, 10636-10644. [CrossRef]

91. Fang, X.; Ma, H.; Xiao, S.; Shen, M.; Guo, R.; Cao, X.; Shi, X. Facile immobilization of gold nanoparticles into electrospun polyethyleneimine/polyvinyl alcohol nanofibers for catalytic applications. J. Mater. Chem. 2011, 21, 4493-4501. [CrossRef]

92. Liu, X.; Li, L.; Ye, M.; Xue, Y.; Chen, S. Polyaniline: Poly(sodium 4-styrenesulfonate)-stabilized gold nanoparticles as efficient, versatile catalysts. Nanoscale 2014, 6, 5223-5229. [CrossRef]

93. Huang, T.; Meng, F.; Qi, L. Facile synthesis and one-dimensional assembly of cyclodextrin-capped gold nanoparticles and their applications in catalysis and surface-enhanced raman scattering. J. Phys. Chem. C 2009, 113, 13636-13642. [CrossRef]

94. Corma, A.; Serna, P. Chemoselective hydrogenation of nitro compounds with supported gold catalysts. Science 2006, 313, 332-334. [CrossRef]

95. Serna, P.; Corma, A. Transforming nano metal nonselective particulates into chemoselective catalysts for hydrogenation of substituted nitrobenzenes. ACS Catal. 2015, 5, 7114-7121. [CrossRef]

96. Corma, A.; Concepción, P.; Serna, P. A different reaction pathway for the reduction of aromatic nitro compounds on gold catalysts. Angew. Chem. Int. Ed. 2007, 46, 7266-7269. [CrossRef]

97. Combita, D.; Concepción, P.; Corma, A. Gold catalysts for the synthesis of aromatic azocompounds from nitroaromatics in one step. J. Catal. 2014, 311, 339-349. [CrossRef]

98. Smith, M.B.; March, J. Oxidations and reductions. In March's Advanced Organic Chemistry; John Wiley and Sons, Inc.: Hoboken, NJ, USA, 2006; pp. 1703-1869. [CrossRef]

99. Tojo, G.; Fernandez, M.I. Oxidation of Primary Alcohols to Carboxylic Acids. A Guide to Current Common Practice; Springer: New York, NY, USA, 2007.

100. Mallat, T.; Baiker, A. Potential of gold nanoparticles for oxidation in fine chemical synthesis. Annu. Rev. Chem. Biomol. Eng. 2012, 3, 11-28. [CrossRef]

101. Hashmi, A.S.K.; Hutchings, G.J. Gold catalysis. Angew. Chem. Int. Ed. 2006, 45, 7896-7936. [CrossRef]

102. Corma, A.; Garcia, H. Supported gold nanoparticles as catalysts for organic reactions. Chem. Soc. Rev. 2008, 37, $2096-2126$. [CrossRef]

103. Carabineiro, S.A.C. Supported gold nanoparticles as catalysts for the oxidation of alcohols and alkanes. Front. Chem. 2019, 7. [CrossRef] [PubMed]

104. Della Pina, C.; Falletta, E.; Prati, L.; Rossi, M. Selective oxidation using gold. Chem. Soc. Rev. 2008, 37, 2077-2095. [CrossRef] [PubMed]

105. Tsukuda, T.; Tsunoyama, H.; Sakurai, H. Aerobic oxidations catalyzed by colloidal nanogold. Chem. Asian J. 2011, 6, 736-748. [CrossRef] [PubMed]

106. Takei, T.; Akita, T.; Nakamura, I.; Fujitani, T.; Okumura, M.; Okazaki, K.; Huang, J.; Ishida, T.; Haruta, M. Chapter oneHeterogeneous catalysis by gold. In Advances in Catalysis; Gates, B.C., Jentoft, F.C., Eds.; Academic Press: Cambridge, MA, USA, 2012; Volume 55, pp. 1-126.

107. Davis, S.E.; Ide, M.S.; Davis, R.J. Selective oxidation of alcohols and aldehydes over supported metal nanoparticles. Green Chem. 2013, 15, 17-45. [CrossRef]

108. Sharma, A.S.; Kaur, H.; Shah, D. Selective oxidation of alcohols by supported gold nanoparticles: Recent advances. RSC Adv. 2016, 6, 28688-28727. [CrossRef] 
109. Staykov, A.; Nishimi, T.; Yoshizawa, K.; Ishihara, T. Oxygen activation on nanometer-size gold nanoparticles. J. Phys. Chem. C 2012, 116, 15992-16000. [CrossRef]

110. Montemore, M.M.; van Spronsen, M.A.; Madix, R.J.; Friend, C.M. $\mathrm{O}_{2}$ activation by metal surfaces: Implications for bonding and reactivity on heterogeneous catalysts. Chem. Rev. 2018, 118, 2816-2862. [CrossRef]

111. Teng, B.-T.; Lang, J.-J.; Wen, X.-D.; Zhang, C.; Fan, M.; Harris, H.G. O ${ }_{2}$ adsorption and oxidative activity on gold-based catalysts with and without a ceria support. J. Phys. Chem. C 2013, 117, 18986-18993. [CrossRef]

112. Staykov, A.; Derekar, D.; Yamamura, K. Oxygen dissociation on palladium and gold core/shell nanoparticles. Int. J. Quantum Chem. 2016, 116, 1486-1492. [CrossRef]

113. Zhao, J.; Jin, R. Heterogeneous catalysis by gold and gold-based bimetal nanoclusters. Nano Today 2018, 18, 86-102. [CrossRef]

114. Biella, S.; Castiglioni, G.L.; Fumagalli, C.; Prati, L.; Rossi, M. Application of gold catalysts to selective liquid phase oxidation. Catal. Today 2002, 72, 43-49. [CrossRef]

115. Guo, Z.; Liu, B.; Zhang, Q.; Deng, W.; Wang, Y.; Yang, Y. Recent advances in heterogeneous selective oxidation catalysis for sustainable chemistry. Chem. Soc. Rev. 2014, 43, 3480-3524. [CrossRef]

116. Mallat, T.; Baiker, A. Oxidation of alcohols with molecular oxygen on solid catalysts. Chem. Rev. 2004, 104, 3037-3058. [CrossRef]

117. Besson, M.; Gallezot, P. Selective oxidation of alcohols and aldehydes on metal catalysts. Catal. Today 2000, 57, 127-141. [CrossRef]

118. Biella, S.; Prati, L.; Rossi, M. Selective oxidation of D-glucose on gold catalyst. J. Catal. 2002, 206, 242-247. [CrossRef]

119. Carrettin, S.; McMorn, P.; Johnston, P.; Griffin, K.; Hutchings, G.J. Selective oxidation of glycerol to glyceric acid using a gold catalyst in aqueous sodium hydroxide. Chem. Commun. 2002, 7, 696-697. [CrossRef]

120. Tsunoyama, H.; Sakurai, H.; Negishi, Y.; Tsukuda, T. Size-specific catalytic activity of polymer-stabilized gold nanoclusters for aerobic alcohol oxidation in water. J. Am. Chem. Soc. 2005, 127, 9374-9375. [CrossRef]

121. Balcha, T.; Strobl, J.R.; Fowler, C.; Dash, P.; Scott, R.W.J. Selective aerobic oxidation of crotyl alcohol using AuPd core-shell nanoparticles. ACS Catal. 2011, 1, 425-436. [CrossRef]

122. Shi, P.; Gao, C.; He, X.; Sun, P.; Zhang, W. Multicompartment nanoparticles of poly(4-vinylpyridine) graft block terpolymer: Synthesis and application as scaffold for efficient Au nanocatalyst. Macromolecules 2015, 48, 1380-1389. [CrossRef]

123. Han, J.; Liu, Y.; Li, L.; Guo, R. Poly(o-phenylenediamine) submicrosphere-supported gold nanocatalysts: Synthesis, characterization, and application in selective oxidation of benzyl alcohol. Langmuir 2009, 25, 11054-11060. [CrossRef]

124. Marx, S.; Baiker, A. Beneficial interaction of gold and palladium in bimetallic catalysts for the selective oxidation of benzyl alcohol. J. Phys. Chem. C 2009, 113, 6191-6201. [CrossRef]

125. Lucchesi, C.; Inasaki, T.; Miyamura, H.; Matsubara, R.; Kobayashi, S. Aerobic oxidation of alcohols under mild conditions catalyzed by novel polymer-incarcerated, carbon-stabilized gold nanoclusters. Adv. Synth. Catal. 2008, 350, 1996-2000. [CrossRef]

126. Kaizuka, K.; Miyamura, H.; Kobayashi, S. Remarkable effect of bimetallic nanocluster catalysts for aerobic oxidation of alcohols: Combining metals changes the activities and the reaction pathways to aldehydes/carboxylic acids or esters. J. Am. Chem. Soc. 2010, 132, 15096-15098. [CrossRef] [PubMed]

127. Mertens, P.G.N.; Corthals, S.L.F.; Ye, X.; Poelman, H.; Jacobs, P.A.; Sels, B.F.; Vankelecom, I.F.J.; de Vos, D.E. Selective alcohol oxidation to aldehydes and ketones over base-promoted gold-palladium clusters as recyclable quasihomogeneous and heterogeneous metal catalysts. J. Mol. Catal. A 2009, 313, 14-21. [CrossRef]

128. Li, Y.; Gao, Y.; Yang, C.; Sha, S.; Hao, J.; Wu, Y. Facile synthesis of polystyrene/gold composite particles as a highly active and reusable catalyst for aerobic oxidation of benzyl alcohol in water. RSC Adv. 2014, 4, 24769-24772. [CrossRef]

129. Yuan, Y.; Yan, N.; Dyson, P.J. pH-sensitive gold nanoparticle catalysts for the aerobic oxidation of alcohols. Inorg. Chem. 2011, 50, 11069-11074. [CrossRef] [PubMed]

130. Miyamura, H.; Matsubara, R.; Kobayashi, S. Gold-platinum bimetallic clusters for aerobic oxidation of alcohols under ambient conditions. Chem. Commun. 2008, 17, 2031-2033. [CrossRef]

131. Gong, J.; Mullins, C.B. Surface science investigations of oxidative chemistry on gold. Acc. Chem. Res. 2009, 42, 1063-1073. [CrossRef]

132. Abad, A.; Corma, A.; García, H. Catalyst parameters determining activity and selectivity of supported gold nanoparticles for the aerobic oxidation of alcohols: The molecular reaction mechanism. Chem. Eur. J. 2008, 14, 212-222. [CrossRef]

133. Conte, M.; Miyamura, H.; Kobayashi, S.; Chechik, V. Spin trapping of Au-H intermediate in the alcohol oxidation by supported and unsupported gold catalysts. J. Am. Chem. Soc. 2009, 131, 7189-7196. [CrossRef]

134. Wang, N.; Matsumoto, T.; Ueno, M.; Miyamura, H.; Kobayashi, S. A gold-immobilized microchannel flow reactor for oxidation of alcohols with molecular oxygen. Angew. Chem. Int. Ed. 2009, 48, 4744-4746. [CrossRef]

135. Kanaoka, S.; Yagi, N.; Fukuyama, Y.; Aoshima, S.; Tsunoyama, H.; Tsukuda, T.; Sakurai, H. Thermosensitive gold nanoclusters stabilized by well-defined vinyl ether star polymers: Reusable and durable catalysts for aerobic alcohol oxidation. J. Am. Chem. Soc. 2007, 129, 12060-12061. [CrossRef]

136. Wang, X.; Kawanami, H.; Islam, N.M.; Chattergee, M.; Yokoyama, T.; Ikushima, Y. Amphiphilic block copolymer-stabilized gold nanoparticles for aerobic oxidation of alcohols in aqueous solution. Chem. Commun. 2008, 37, 4442-4444. [CrossRef]

137. Porta, F.; Rossi, M. Gold nanostructured materials for the selective liquid phase catalytic oxidation. J. Mol. Catal. A 2003, 204, 553-559. [CrossRef]

138. Villa, A.; Wang, D.; Su, D.S.; Prati, L. Gold sols as catalysts for glycerol oxidation: The role of stabilizer. ChemCatChem 2009, 1, 510-514. [CrossRef] 
139. Ishida, T.; Okamoto, S.; Makiyama, R.; Haruta, M. Aerobic oxidation of glucose and 1-phenylethanol over gold nanoparticles directly deposited on ion-exchange resins. Appl. Catal. A 2009, 353, 243-248. [CrossRef]

140. Toshima, N.; Zhang, H. Polymer-protected and Au-containing Bi- and trimetallic nanoparticles as novel catalysts for glucose oxidation. Macromol. Symp. 2012, 317, 149-159. [CrossRef]

141. Berndt, H.; Pitsch, I.; Evert, S.; Struve, K.; Pohl, M.M.; Radnik, J.; Martin, A. Oxygen adsorption on $\mathrm{Au} / \mathrm{Al}_{2} \mathrm{O}_{3}$ catalysts and relation to the catalytic oxidation of ethylene glycol to glycolic acid. Appl. Catal. A 2003, 244, 169-179. [CrossRef]

142. Murugadoss, A.; Sakurai, H. Chitosan-stabilized gold, gold-palladium, and gold-platinum nanoclusters as efficient catalysts for aerobic oxidation of alcohols. J. Mol. Catal. A 2011, 341, 1-6. [CrossRef]

143. Schumperli, M.T.; Hammond, C.; Hermans, I. Developments in the aerobic oxidation of amines. ACS Catal. 2012, 2, 1108-1117. [CrossRef]

144. Zhu, B.; Angelici, R.J. Non-nanogold catalyzed aerobic oxidation of secondary amines to imines. Chem. Commun. 2007, 21, 2157-2159. [CrossRef]

145. Aschwanden, L.; Mallat, T.; Grunwaldt, J.-D.; Krumeich, F.; Baiker, A. Gold-catalyzed aerobic oxidation of dibenzylamine: Homogeneous or heterogeneous catalysis? J. Mol. Catal. A 2009, 300, 111-115. [CrossRef]

146. Aschwanden, L.; Mallat, T.; Krumeich, F.; Baiker, A. A simple preparation of an efficient heterogeneous gold catalyst for aerobic amine oxidation. J. Mol. Catal. A 2009, 309, 57-62. [CrossRef]

147. Aschwanden, L.; Panella, B.; Rossbach, P.; Keller, B.; Baiker, A. Magnetically separable gold catalyst for the aerobic oxidation of amines. ChemCatChem 2009, 1, 111-115. [CrossRef]

148. Aschwanden, L.; Mallat, T.; Maciejewski, M.; Krumeich, F.; Baiker, A. Development of a new generation of gold catalysts for amine oxidation. Chem CatChem 2010, 2, 666-673. [CrossRef]

149. Grirrane, A.; Corma, A.; Garcia, H. Highly active and selective gold catalysts for the aerobic oxidative condensation of benzylamines to imines and one-pot, two-step synthesis of secondary benzylamines. J. Catal. 2009, 264, 138-144. [CrossRef]

150. Miyamura, H.; Morita, M.; Inasaki, T.; Kobayashi, S. Aerobic oxidation of amines catalyzed by polymer-incarcerated Au nanoclusters: Effect of cluster size and cooperative functional groups in the polymer. Bull. Chem. Soc. Jpn. 2011, 84, 588-599. [CrossRef]

151. Miyamura, H.; Yasukawa, T.; Kobayashi, S. Aerobic oxidative esterification of alcohols catalyzed by polymer-incarcerated gold nanoclusters under ambient conditions. Green Chem. 2010, 12, 776-778. [CrossRef]

152. Soulé, J.-F.; Miyamura, H.; Kobayashi, S. Powerful amide synthesis from alcohols and amines under aerobic conditions catalyzed by gold or gold/iron, -nickel or -cobalt nanoparticles. J. Am. Chem. Soc. 2011, 133, 18550-18553. [CrossRef]

153. Soulé, J.-F.; Miyamura, H.; Kobayashi, S. Selective imine formation from alcohols and amines catalyzed by polymer incarcerated gold/palladium alloy nanoparticles with molecular oxygen as an oxidant. Chem. Commun. 2013, 49, 355-357. [CrossRef]

154. Zhang, L.; Wang, W.; Wang, A.; Cui, Y.; Yang, X.; Huang, Y.; Liu, X.; Liu, W.; Son, J.-Y.; Oji, H.; et al. Aerobic oxidative coupling of alcohols and amines over $\mathrm{Au}-\mathrm{Pd} /$ resin in water: $\mathrm{Au} / \mathrm{Pd}$ molar ratios switch the reaction pathways to amides or imines. Green Chem. 2013, 15, 2680-2684. [CrossRef]

155. Shi, F.; Zhang, Q.; Ma, Y.; He, Y.; Deng, Y. From $\mathrm{CO}$ oxidation to $\mathrm{CO}_{2}$ activation: An unexpected catalytic activity of polymersupported nanogold. J. Am. Chem. Soc. 2005, 127, 4182-4183. [CrossRef] [PubMed]

156. Xiang, D.; Liu, X.; Sun, J.; Xiao, F.-S.; Sun, J. A novel route for synthesis of styrene carbonate using styrene and $\mathrm{CO}_{2}$ as substrates over basic resin R201 supported Au catalyst. Catal. Today 2009, 148, 383-388. [CrossRef]

157. Preedasuriyachai, P.; Kitahara, H.; Chavasiri, W.; Sakurai, H. N-formylation of amines catalyzed by nanogold under aerobic oxidation conditions with MeOH or formalin. Chem. Lett. 2010, 39, 1174-1176. [CrossRef]

158. Preedasuriyachai, P.; Chavasiri, W.; Sakurai, H. Aerobic oxidation of cyclic amines to lactams catalyzed by PVP-stabilized nanogold. Synlett 2011, 2011, 1121-1124. 